\title{
Review Article \\ Chiral Recognition by Fluorescence: One Measurement for Two Parameters
}

\author{
Shanshan $Y u^{1}$ and Lin $P u^{2}$ \\ ${ }^{1}$ Key Laboratory of Green Chemistry and Technology, Ministry of Education, College of Chemistry, \\ Sichuan University, Chengdu 610064, China \\ ${ }^{2}$ Department of Chemistry, University of Virginia, Charlottesville, VA 22904, USA \\ Correspondence should be addressed to Shanshan Yu; yushanshan@scu.edu.cn and Lin Pu; lp6n@virginia.edu
}

Received 3 February 2014; Accepted 11 June 2014; Published 23 July 2014

Academic Editor: João A. Lopes

Copyright (C) 2014 S. Yu and L. Pu. This is an open access article distributed under the Creative Commons Attribution License, which permits unrestricted use, distribution, and reproduction in any medium, provided the original work is properly cited.

\begin{abstract}
This outlook describes two strategies to simultaneously determine the enantiomeric composition and concentration of a chiral substrate by a single fluorescent measurement. One strategy utilizes a pseudoenantiomeric sensor pair that is composed of a $1,1^{\prime}-$ bi-2-naphthol-based amino alcohol and a partially hydrogenated 1,1'-bi-2-naphthol-based amino alcohol. These two molecules have the opposite chiral configuration with fluorescent enhancement at two different emitting wavelengths when treated with the enantiomers of mandelic acid. Using the sum and difference of the fluorescent intensity at the two wavelengths allows simultaneous determination of both concentration and enantiomeric composition of the chiral acid. The other strategy employs a $1,1^{\prime}$-bi-2naphthol-based trifluoromethyl ketone that exhibits fluorescent enhancement at two emission wavelengths upon interaction with a chiral diamine. One emission responds mostly to the concentration of the chiral diamine and the ratio of the two emissions depends on the chiral configuration of the enantiomer but independent of the concentration, allowing both the concentration and enantiomeric composition of the chiral diamine to be simultaneously determined. These strategies would significantly simplify the practical application of the enantioselective fluorescent sensors in high-throughput chiral assay.
\end{abstract}

\section{Introduction}

The study of enantiomerically pure chiral compounds has found increasing importance in many areas, such as pharmaceutical industry $[1,2]$, agrochemical area [3], and food analysis $[4,5]$. For example, the stereochemistry of drugs can significantly affect their biological activity due to the inherently chiral environment of the biological systems. The US FDA issued a policy statement in 1992 and strongly encouraged the development of single isomers [6]. Therefore, easily and economically performed methods for acquiring enantiopure compounds have attracted enormous research interest.

The development of asymmetric catalysis has provided the pathway to preferentially generate one enantiomer over the other from a reaction by using a chiral catalyst. This not only can avoid the labor-intensive and time-consuming separation of enantiomers, but also can eliminate the waste of the undesired enantiomer $[7,8]$. The key to develop an efficient asymmetric catalysis reaction is to identify a catalyst structure as well as its most suitable reaction conditions including factors such as solvent, temperature, additive, reaction time, and stoichiometry. Therefore, this screening process can be extremely time-consuming with the traditional one-catalystat-a-time approach. The emergence of combinatorial chemistry and parallel synthesis in the 1990s has made it possible to conduct efficient high-throughput screening of an enormous number of chiral catalysts [9-13]. With the assistance of the highly automated system, tens of thousands of compounds can be prepared in a short period of time. However, with the traditional analytical techniques, such as gas chromatography (GC) or high-performance liquid chromatography (HPLC), it usually takes about $20 \mathrm{~min}$ to determine the enantiomeric composition of a sample, which would be very inefficient for the analysis of the great number of products generated from the combinatorial catalyst screening processes. Therefore, high-throughput analytical techniques have become the bottleneck for the combinatorial chiral catalyst screening. 
To date, a number of techniques are under development for the high-throughput enantiomeric composition determination [13-17], including time resolved IR-thermographic method [18-21], electron spray mass spectrometry [2226], capillary electrophoresis [27], UV/Vis [28-30], circular dichroism [31, 32], and fluorescence [33, 34]. Among these approaches, optical methods have been attracting increasing attention due to their ability for quick data collection and compatibility with high-throughput screening system. Anslyn has recently reviewed the optical approaches for the rapid enantiomeric composition determination [17]. For an asymmetrical catalytic reaction, both the yield and enantiomeric purity of the product are the essential two parameters needed to evaluate the efficiency of a chiral catalyst. Therefore, a high-throughput analytical process would require a rapid determination of both the concentration and enantiomeric purity of the chiral substrate. This would normally need two independent methods one measuring the concentration and one measuring the enantiomeric purity. It would be highly advantageous if both parameters of a reaction could be determined by a single measurement.

Recently, several strategies have been developed to measure both the concentration and enantiomeric purity of a chiral compound. Wolf and coworkers measured the concentration and enantiomeric composition of chiral compounds by using racemic and enantiopure forms of a chiral sensor in tandem with UV or fluorescence measurement [35-38]. By employing rapidly interconverting racemic sensors, they also fulfilled the same task with dual-mode optical measurements of a sample solution. They used the induced CD signal of the sensor in the presence of the chiral substrate to quantify the enantiomeric purity and then used the chirality independent UV or FL responses to quantify the substrate concentration $[39,40]$. Anslyn and coworkers established enantioselective indicator displacement assays (eIDA), with which achiral and chiral sensors were used to determine the concentration and enantiomeric purity of a chiral sample, respectively [41]. To reduce the number of spectroscopic measurements from two to one, they utilized a dual-chamber quartz cuvette filled with careful choice of indicator/host combinations [42], with which information about the two samples in these two chambers can be acquired at two distinct wavelengths with a single spectroscopic measurement. They further employed the use of artificial neural networks (ANNs) to fingerprint chemical identity, concentration, and chirality of chiral compounds $[43,44]$.

In the past decade, our laboratory has been working on the development of enantioselective fluorescent sensors for chiral organic molecules [45-54]. We have chosen the optically active $1,1^{\prime}$-bi-2-naphthol (BINOL) as the chiral structural unit to construct the sensors (Figure 1). The hindered rotation of the two naphthyl rings of BINOL leads to a stable $C_{2}$ symmetric chiral configuration. Functional groups can be selectively introduced to the 2-, 3-, 4-, 5-, and 6positions of BINOL to build various molecular structures. These functional groups also allow the fluorescence property of the naphthalene rings to be tuned for the desired sensing response. Through this study, we have discovered a series of the BINOL-based enantioselective fluorescent

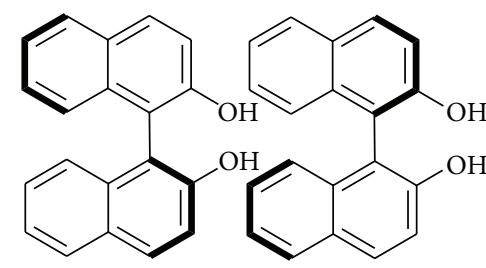

(S)-BINOL

(R)-BINOL

Figure 1: (S)-BINOL and (R)-BINOL.

sensors as shown in Figure 2 for the recognition of chiral $\alpha$ hydroxycarboxylic acids, amino alcohols, amines, and amino acid derivatives with high enantioselectivity [55-58]. These sensors include the generation 0-2 (G0-G2) dendrimers, $(S)$ 1, $(S)-\mathbf{2}$, and $(S)-\mathbf{3}$, the BINOL-terpyridine copper complex $(R)-4$, the monoamine-linked bisBINOL sensor $(S)-5$, the bisBINOL-based macrocyclic sensors $(S)-6$ and $(S)-7$, and the monoBINOL-based sensors $(S)-8$ and $(S)-9$. The highly enantioselective fluorescent responses of these compounds make them useful in determining the enantiomeric composition of various chiral substrates.

As discussed earlier, if both the concentration and enantiomeric composition of a chiral substrate could be determined by using one fluorescent measurement, it would significantly simplify the practical application of the enantioselective fluorescent recognition. We have developed two strategies to achieve this goal of one measurement for two parameters and these strategies are discussed in this paper.

\section{Using Pseudoenantiomeric Fluorescent Sensor Pair for the Simultaneous Determination of the Concentration and Enantiomeric Composition of a Chiral Substrate [59]}

We have discovered that the BINOL-based amino alcohol $(S)$ 9 is a generally enantioselective fluorescent sensor for structurally diverse $\alpha$-hydroxycarboxylic acids [58]. As shown in Figure 3, $(R)$-phenyllactic acid significantly enhances the monomer emission of sensor $(S)-9$ while $(S)$-phenyllactic acid quenches it in benzene/ $0.4 \%$ DME solution. The fluorescent intensity ratio $I_{R} / I_{S}$ is used to quantify the enantioselectivity, which is as high as 11.2 for phenyllactic acid. Figure 4 summarizes the $I_{R} / I_{S}$ ratio when $(S)-9$ is used to interact with various $\alpha$-hydroxyl carboxylic acids, including aromatic, aliphatic, and tertiary $\alpha$-hydroxyl carboxylic acids, under the same conditions and very high enantioselectivity is generally observed for all the tested chiral acids. Therefore, $(S)-9$ can be used to determine the enantiomeric purity of various types of $\alpha$-hydroxyl carboxylic acids.

Our ${ }^{1} \mathrm{H}$ NMR spectroscopic study indicates the formation of $1: 1$ sensor/acid complex. The computational simulation of the $1: 1$ complex of $(S)-9$ and phenyllactic acid was performed with the Gaussian 03 program. The proposed structure of the complex is shown in Figure 5. Strong acid-base interaction between the carboxylic acid group and the amine nitrogen 

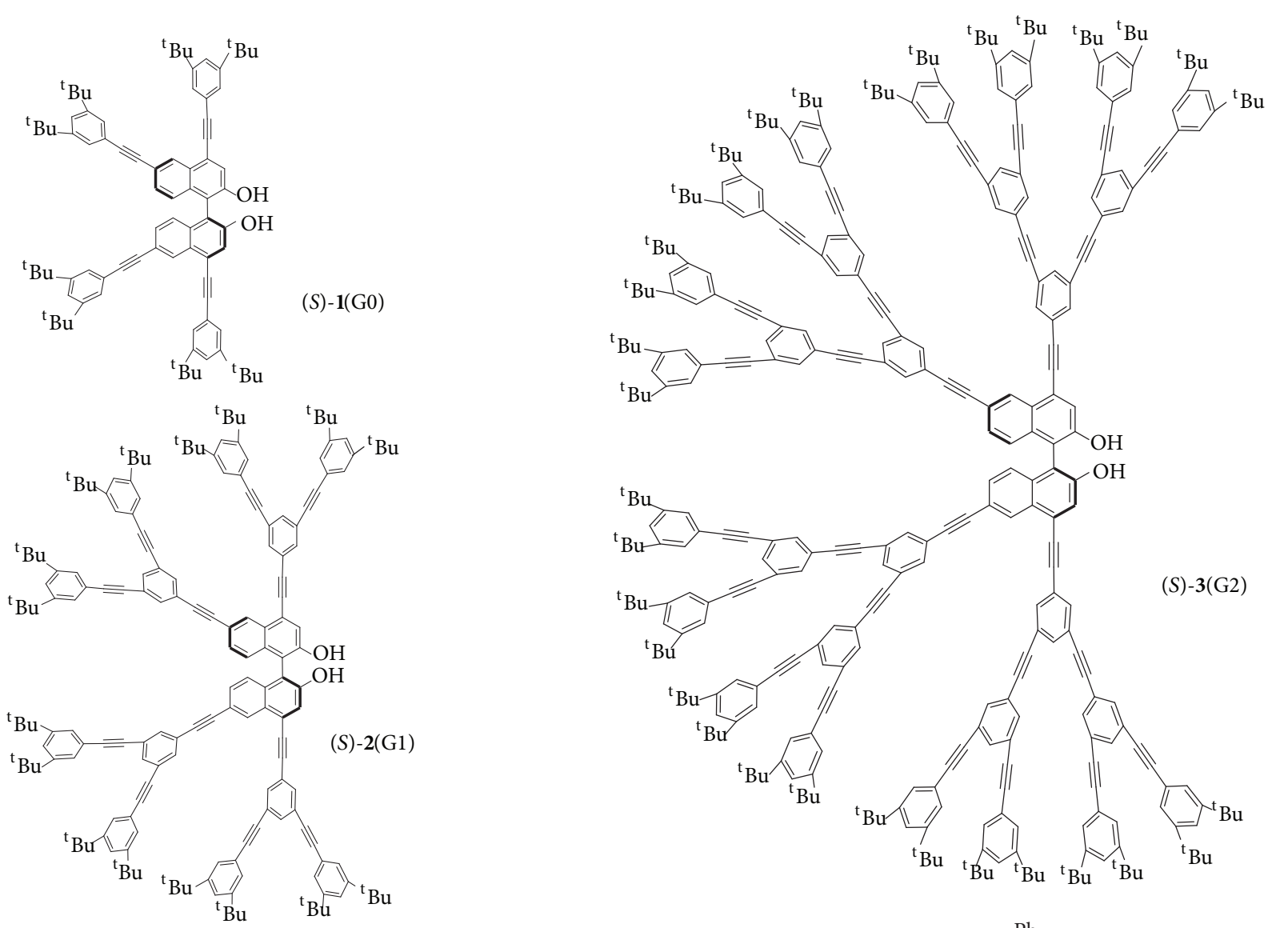

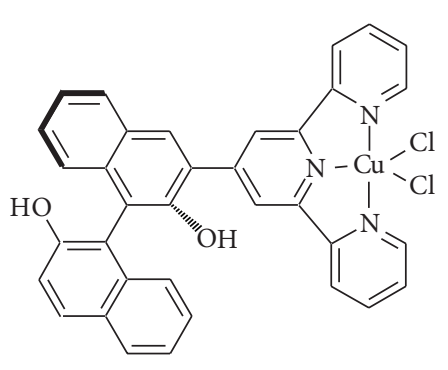

$(R)-4$

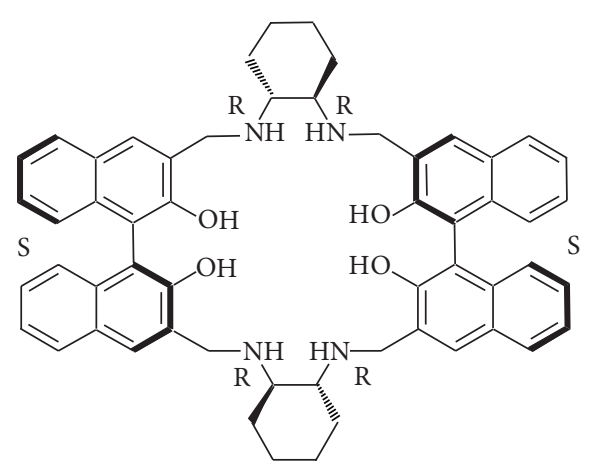

$(S)-7$

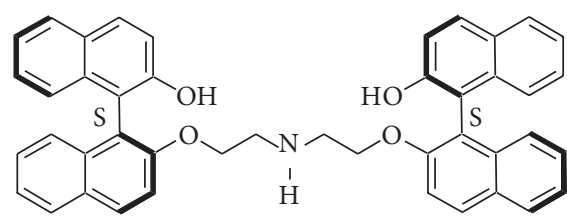

(S)-5

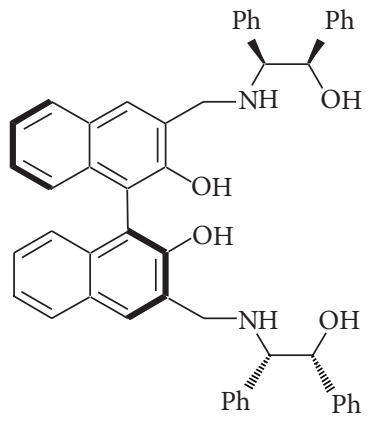

(S)-8
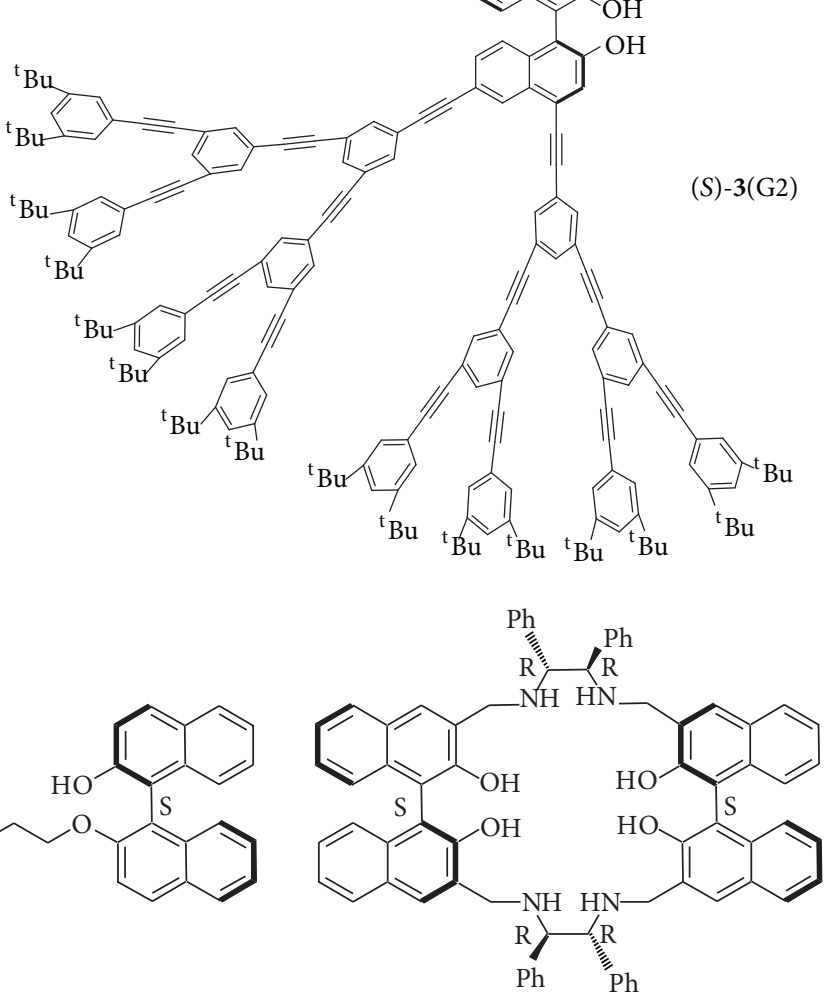

(S)-6

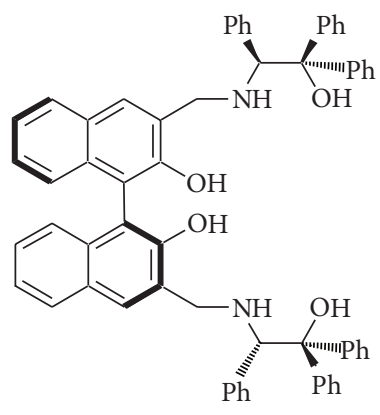

$(S)-9$

FIGURE 2: BINOL-based enantioselective fluorescent sensors. 


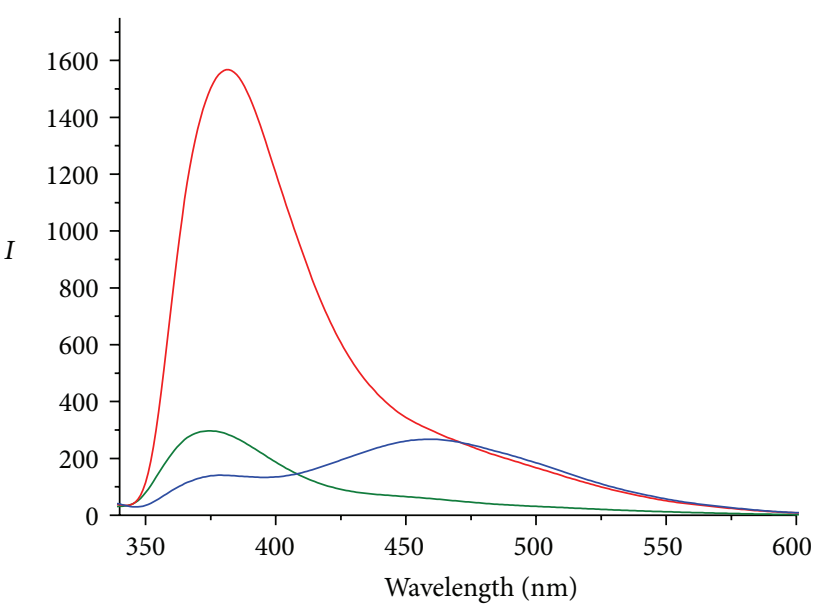

\begin{tabular}{ll}
- & $(S)-\mathbf{9}+(R)$-acid \\
\hline & $(S)-\mathbf{9}$ \\
\hline & $(S)-9+(S)$-acid
\end{tabular}

(a)

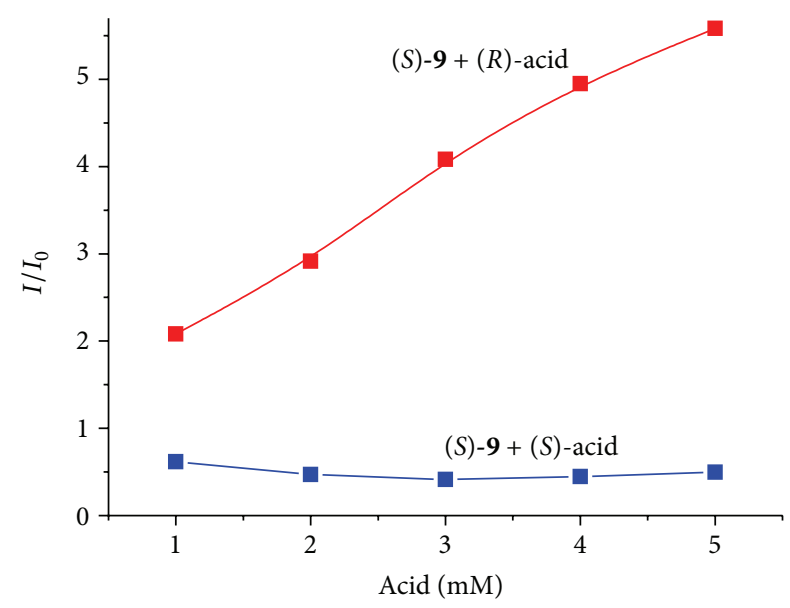

(b)

Figure 3: (a) Fluorescence spectra of $(S)-9\left(2 \times 10^{-4} \mathrm{M}\right.$, benzene/0.4\% v/v DME) with $(R)$ - and $(S)$-phenyllactic acid $\left(5 \times 10^{-3} \mathrm{M}\right)$. (b) Fluorescence enhancement of $(S)$-9 with varying concentrations of $(R)$ - and $(S)$-phenyllactic acid $(\lambda=334 \mathrm{~nm}$, slit $=5.0 / 5.0 \mathrm{~nm})($ permission was obtained from Wiley to reproduce this plot).<smiles>O=C(O)C(O)c1ccccc1</smiles><smiles>O=C(O)C(O)Cc1ccccc1</smiles><smiles>O=C(O)C(O)C1CCCCC1</smiles>

$I_{R} / I_{S}=25.8$

$$
I_{R} / I_{S}=13.0
$$<smiles>O=C(O)C(O)CC1CCCCC1</smiles>

$I_{R} / I_{S}=22.8$<smiles>CC(C)C(O)C(=O)O</smiles>

$I_{R} / I_{S}=11.2$<smiles>CC(O)(C(=O)O)c1ccccc1</smiles>

$I_{R} / I_{S}=13.0$<smiles>CCC(O)C(=O)O</smiles>

$I_{R} / I_{S}=13.9$<smiles>CC(O)(C(=O)O)c1ccccc1Cl</smiles>

$I_{R} / I_{S}=2.4$

FIgURE 4: Fluorescent enantioselectivity of (S)-9 toward various chiral $\alpha$-hydroxycarboxylic acids.

of (S)-9 exists in the complex. The carbonyl oxygen of phenyllactic acid forms hydrogen bonding with a hydroxyl group of (S)-9. The $\alpha$-hydroxyl group of the acid is also hydrogen-bonded with both hydroxyl groups of the amino alcohol units in (S)-9.

The highly enantioselective fluorescent responses of $(S)$ 9 toward the $\alpha$-hydroxycarboxylic acids allow the use of this molecule to determine the enantiomeric composition of the substrates at a given concentration. In order to simultaneously determine both the concentration and enantiomeric composition of a chiral acid, we have proposed a novel strategy by developing a pseudoenantiomeric sensor pair. A pseudoenantiomeric sensor pair contains two sensors with the opposite enantioselectivity at distinct emitting wavelengths $\lambda_{1}$ and $\lambda_{2}$. It is our hypothesis that when such a pseudoenantiomeric sensor pair is used to interact with a chiral substrate, the fluorescent intensity difference $I_{1}-I_{2}$ at the two emitting wavelengths could be correlated with the enantiomeric composition and the fluorescent intensity sum $I_{1}+I_{2}$ could be correlated with the concentration of the chiral substrate. Thus, both the concentration and enantiomeric composition could be determined simultaneously by one fluorescent measurement.

In order to develop the pseudoenantiomer of (S)-9, compound $(R)-10$ was synthesized according to Scheme 1 . The partially hydrogenated BINOL, $\mathrm{H}_{8} \mathrm{BINOL}$, was used as the starting material. Compound $(R)-\mathbf{1 0}$ contains less extended conjugation and is thus expected to emit at shorter wavelength than the BINOL-based sensor (S)-9. These two compounds have the opposite configurations at the axially chiral biaryl unit and the chiral amino carbons, which should give them the opposite enantioselectivity in a chiral recognition experiment.

Both $(S)-9$ and $(R)-10$ were used to interact with $(R)$ and $(S)$-mandelic acid (MA) in dichloromethane (DCM). The benzene/DME solvent system initially reported for the use of (S)-9 is not suitable for this pseudoenantiomeric sensor pair because of the interference of benzene with the fluorescence of $(R)-10$ as the conjugation of $(R)-10$ is reduced. We found that changing the solvent from benzene to DCM did not 


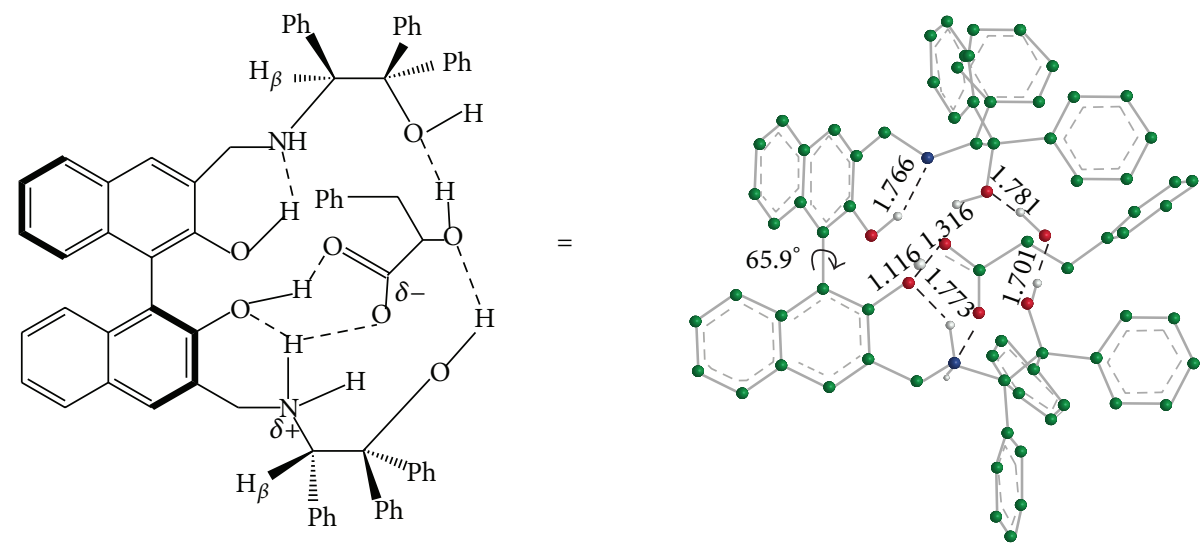

Figure 5: Proposed structure of the 1:1 complex of $(S)-9+(R)$-phenyllactic acid (permission was obtained from Wiley to reproduce this plot).

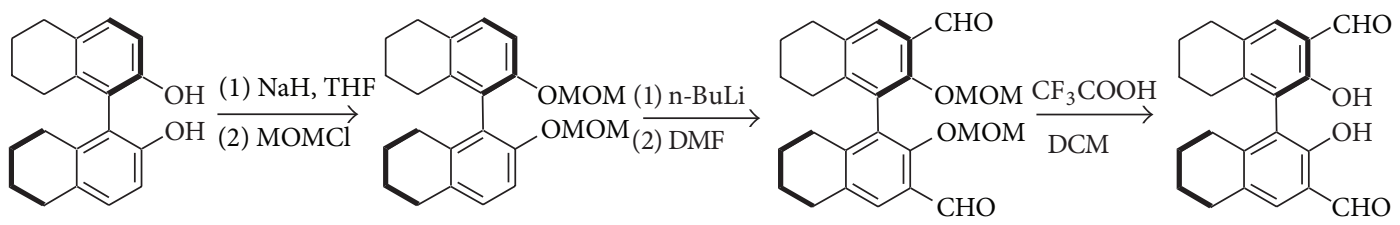

(R)- $\mathrm{H}_{8} \mathrm{BINOL}$

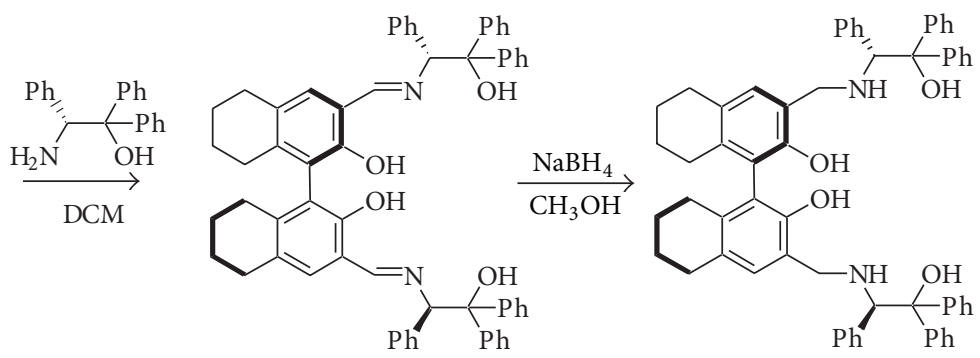

$(R)-10$

Scheme 1: Synthesis of the $\mathrm{H}_{8}$ BINOL-amino alcohol (R)-10.

impair the high enantioselectivity of (S)-9. As shown in Figure 6, treatment with $(R)$-MA significantly enhanced the fluorescent intensity of $(S)-9$ at $374 \mathrm{~nm}\left(\lambda_{1}\right)$, whereas $(S)$-MA only slightly increased its fluorescence. $I_{R} / I_{0}$ is found to be 11.4 and the enantioselective fluorescent enhancement ratio [ef $\left.=\left(I_{R}-I_{0}\right) /\left(I_{S}-I_{0}\right)\right]$ is 26.0. (R)-10 also exhibited high but opposite enantioselectivity for the recognition of MA. As shown in Figure 7, $(S)$-MA enhanced the fluorescence of $(R)$ 10 at $330 \mathrm{~nm}\left(\lambda_{2}\right)$ to a much greater extent than $(R)$-MA did. It was found that $I_{S} / I_{0}=11.7$ and ef $=3.6$.

The above experiments demonstrate that $(S)-9$ and $(R)$ 10 have high and opposite enantioselectivity at two distinct wavelengths $\left(\lambda_{1}=374 \mathrm{~nm}, \lambda_{2}=330 \mathrm{~nm}\right)$ for the recognition of MA, which makes them excellent candidates for a pseudoenantiomeric sensor pair. A 1:1 mixture of $(S)-9$ and $(R)$ 10 in DCM was used to interact with MA of varying concentrations and enantiomeric compositions. As we proposed, the difference of the fluorescence intensities at $\lambda_{1}$ and $\lambda_{2}$ could be utilized to measure the enantiomeric composition of MA and the sum could measure the total concentration. In Figure 8(a), the fluorescent intensity difference at $\lambda_{1}$ and $\lambda_{2}\left(I_{1} / I_{10}-I_{2} / I_{20}, I_{1}\right.$ : the fluorescence intensity at $\lambda_{1}=$ $374 \mathrm{~nm}$ in the presence of MA, $I_{10}$ : the fluorescence intensity at $\lambda_{1}=374 \mathrm{~nm}$ in the absence of MA, $I_{2}$ : the fluorescence intensity at $\lambda_{2}=330 \mathrm{~nm}$ in the presence of MA, and $I_{\mathbf{2 0}}$ : the fluorescence intensity at $\lambda_{2}=330 \mathrm{~nm}$ in the absence of MA) increases with increasing $(R)-\mathrm{MA} \%$ at each total concentration. In Figure 8(b), the fluorescent intensity sum $\left(I_{1} / I_{10}+I_{2} / I_{20}\right)$ increases with increasing MA concentration at each enantiomeric composition.

The $3 \mathrm{D}$ graphs of the total acid concentration and the enantiomeric composition versus the sum and the difference of fluorescent intensities at $\lambda_{1}$ and $\lambda_{2}$ were plotted in Figure 9 on the basis of the data in Figure 8. One fluorescent measurement will give the fluorescent intensities $I_{1}$ and $I_{2}$ which will be used to determine both the concentration 

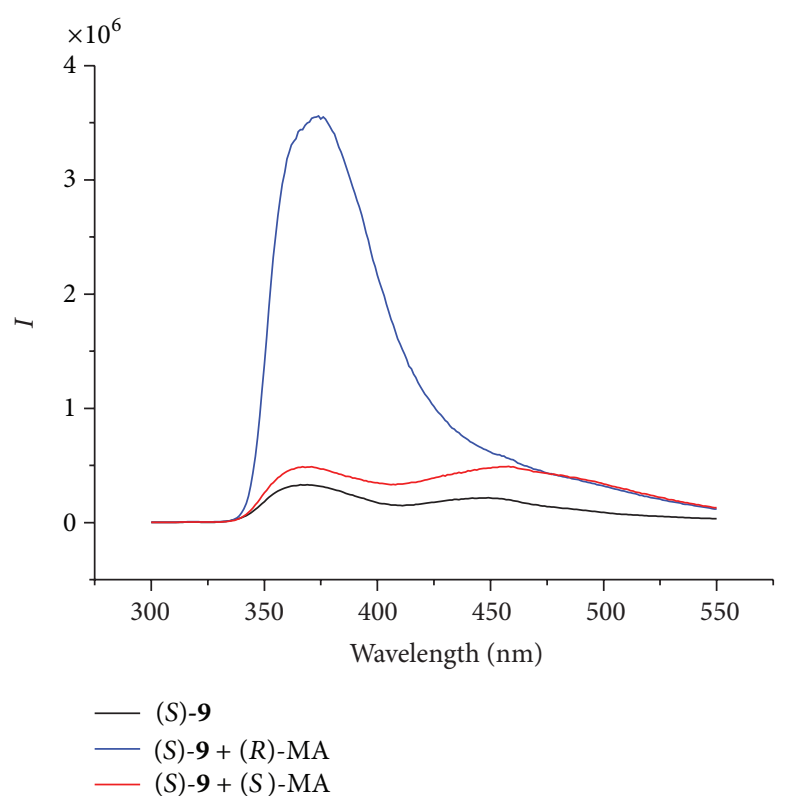

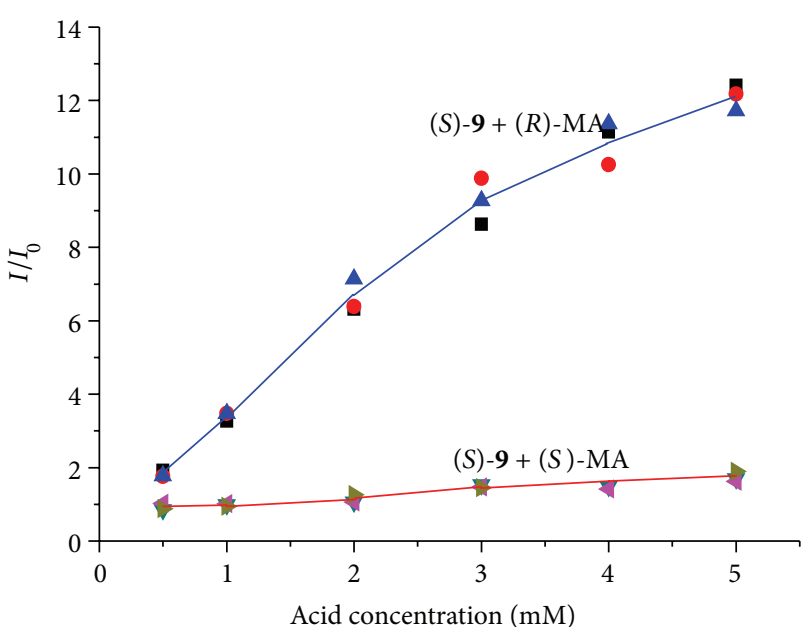

(b)

Figure 6: (a) Fluorescence spectra of $(S)-9\left(1.0 \times 10^{-4} \mathrm{M}, \mathrm{CH}_{2} \mathrm{Cl}_{2}\right)$ with/without $\mathrm{MA}\left(4.0 \times 10^{-3} \mathrm{M}\right)$. (b) Three independent measurements for the fluorescence enhancement of $(S)-9\left(1.0 \times 10^{-4} \mathrm{M}, \mathrm{CH}_{2} \mathrm{Cl}_{2}\right)$ at $\lambda_{1}=374 \mathrm{~nm}$ with varying MA concentration $\left(\lambda_{\text {exc }}=290 \mathrm{~nm}\right.$, slit $=$ 4.0/4.0 nm). Reprinted with permission from [59]. Copyright [2010] American Chemical Society.

and enantiomeric composition of MA according to Figure 9. Thus, the pseudoenantiomeric sensor pair strategy allows one measurement for the two parameters of a chiral compound.

\section{Using One Fluorescent Sensor to Determine Both Concentration and Enantiomeric Composition in One Fluorescence Measurement}

As described in the above section, the pseudoenantiomeric sensor pair strategy is successfully used to simultaneously determine the concentration and enantiomeric composition of a chiral substrate. This strategy requires the use of a mixture of two fluorescent sensors, a pseudoenantiomeric pair. Prompted by this work, we propose another strategy to measure both the concentration and enantiomeric composition by using only one fluorescent sensor. That is, a fluorescent sensor that shows different fluorescent responses at two emitting wavelengths toward the two enantiomers of a chiral substrate will be developed. Such a dual emission sensor could be used to simultaneously measure the total concentration of the two enantiomers as well as their relative concentration (enantiomeric composition) $[60,61]$.

We found that the BINOL-based trifluoromethyl ketone molecule $(S)$-11 could serve as such a dual emission sensor. Scheme 2 depicts the synthesis of (S)-11. This compound was nonemissive at all in methylene chloride solution. The ${ }^{1} \mathrm{H}$ NMR spectrum of (S)-11 indicates the existence of intramolecular $\mathrm{OH} \cdots \mathrm{O}=\mathrm{C}$ hydrogen bonds. Treatment of this compound with both enantiomers of trans-1,2diaminocyclohexane, $(R, R)$ - and $(S, S)-\mathbf{1 2}$, turned on the fluorescence at $\lambda_{1}=370 \mathrm{~nm}$ and $\lambda_{2}=384 \mathrm{~nm}$ (Figure 10). At $\lambda_{1}$, both $(R, R)$ - and $(S, S)$-12 enhanced the fluorescence of $(S)$-11 to a similar extent while at $\lambda_{2},(R, R)$-12 enhanced the fluorescence much greater than $(S, S)$-12. Thus, the two emitting wavelengths of $(S)$-11 responded to the enantiomers of the diamine differently with high fluorescent sensitivity at $\lambda_{1}$ and high enantioselectivity at $\lambda_{2}$.

The effect of the concentration of the chiral diamine $\mathbf{1 2}$ on the fluorescent responses of $(S)-11$ at $\lambda_{1}$ and $\lambda_{2}$ is shown in Figure 11. It demonstrates that the fluorescent intensity $I_{1}$ is strongly dependent on the concentration of the diamine but not significantly on its chiral configuration. The fluorescent intensity ratio $I_{1} / I_{2}$ remains constant at 2.6 for $(R, R)-\mathbf{1 2}$ and at 0.67 for $(S, S)-12$ in the concentration range of 5.0 $\times 10^{-4} \mathrm{M}$ to $5.0 \times 10^{-3} \mathrm{M}$. This shows that $I_{1} / I_{2}$ is strongly dependent on the chiral configuration of the chiral diamine but independent of the concentration. Therefore, $I_{1}$ mostly responds to the concentration of the chiral diamine and $I_{1} / I_{2}$ only responds to the chiral configuration. Another example of chiral diamine, 1,2-diaminopropane, was also tested and similar fluorescent responses at $\lambda_{1}$ and $\lambda_{2}$ were observed.

(S)-11 $\left(1.0 \times 10^{-5} \mathrm{M}\right.$ in $\left.\mathrm{CH}_{2} \mathrm{Cl}_{2}\right)$ was used to interact with varying concentrations and enantiomeric compositions of the chiral diamine 12. Figure 12 plots the fluorescent intensity ratio $I_{1} / I_{2}$ versus $(S, S)-12 \%$ at various diamine concentrations $(0.5-5 \mathrm{mM})$. It demonstrates that the enantiomeric composition of the chiral diamine $\mathbf{1 2}$ can be determined by the fluorescent intensity ratio $I_{1} / I_{2}$ without the need to know the total concentration. Figure 13 plots the total concentration of the chiral diamine 12 versus $I_{1}$ and $I_{1} / I_{2}$. Since the chiral configuration of the diamine $\mathbf{1 2}$ had a small effect on 
$(R)-\mathbf{1 0}+(S)-\mathrm{MA}$

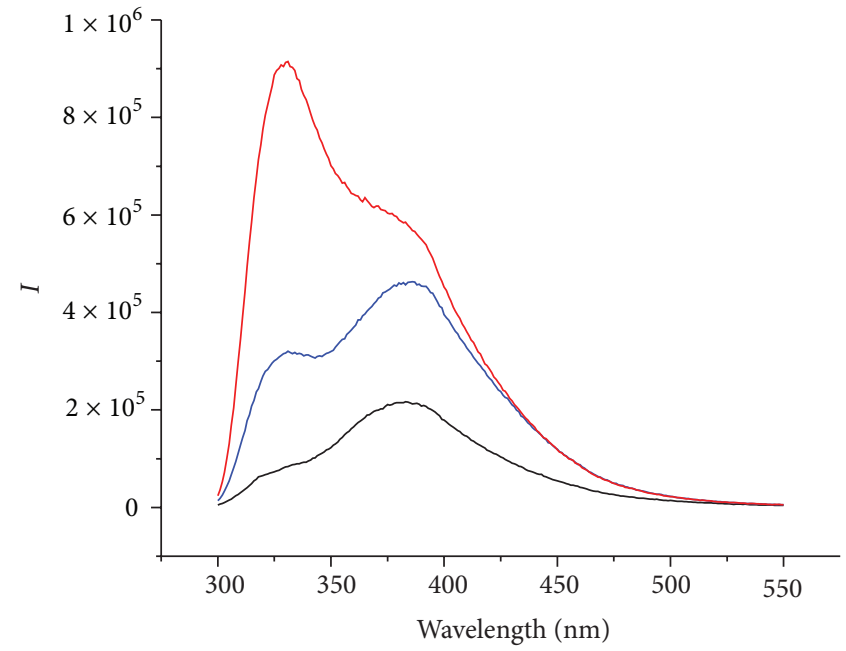

$(R)-10$

$(R)-10+(S)-\mathrm{MA}$

(a)

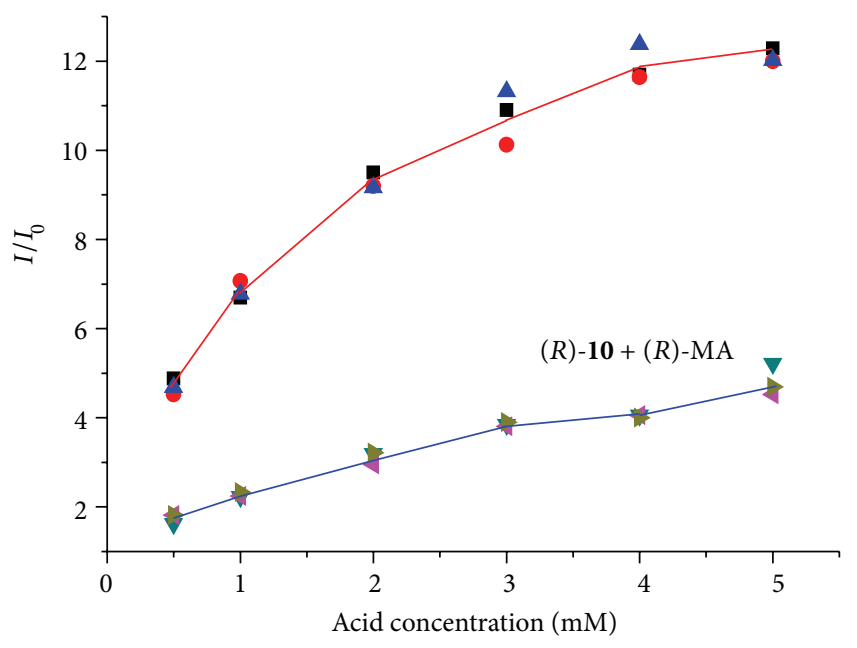

(b)

Figure 7: (a) Fluorescence spectra of $(R)-10\left(1.0 \times 10^{-4} \mathrm{M}, \mathrm{CH}_{2} \mathrm{Cl}_{2}\right)$ with/without $(R)$ - and $(S)$-MA $\left(4.0 \times 10^{-3} \mathrm{M}\right)$. (b) Three independent measurements for the fluorescence enhancement of $(R)-10\left(1.0 \times 10^{-4} \mathrm{M}, \mathrm{CH}_{2} \mathrm{Cl}_{2}\right)$ at $\lambda_{2}=330 \mathrm{~nm}$ with varying $\mathrm{MA}$ concentration $\left(\lambda_{\text {exc }}=\right.$ $290 \mathrm{~nm}$, slit $=4.0 / 4.0 \mathrm{~nm}$ ). Reprinted with permission from [59]. Copyright [2010] American Chemical Society.

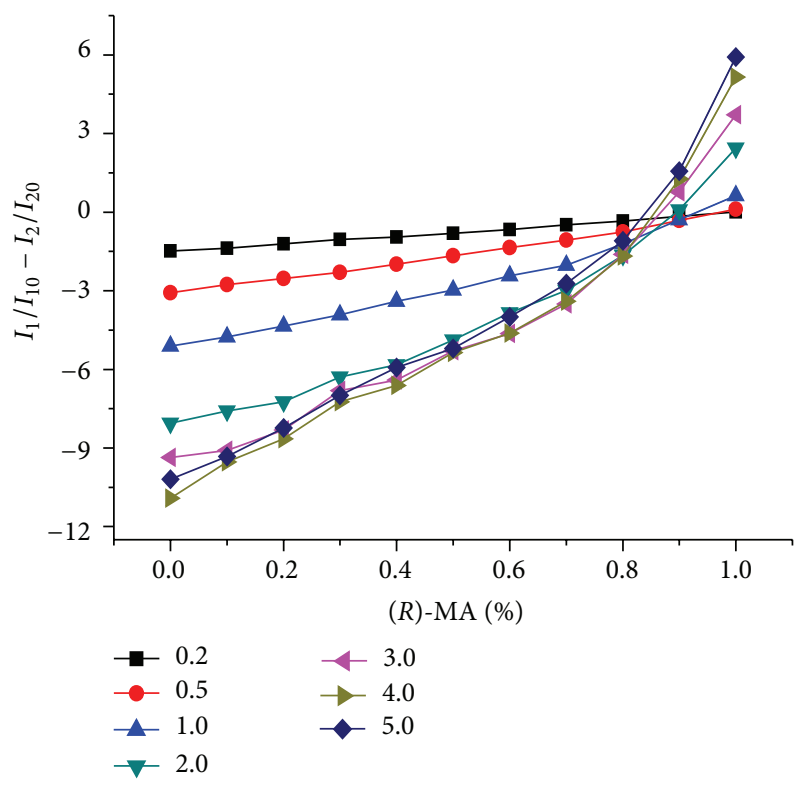

(a)

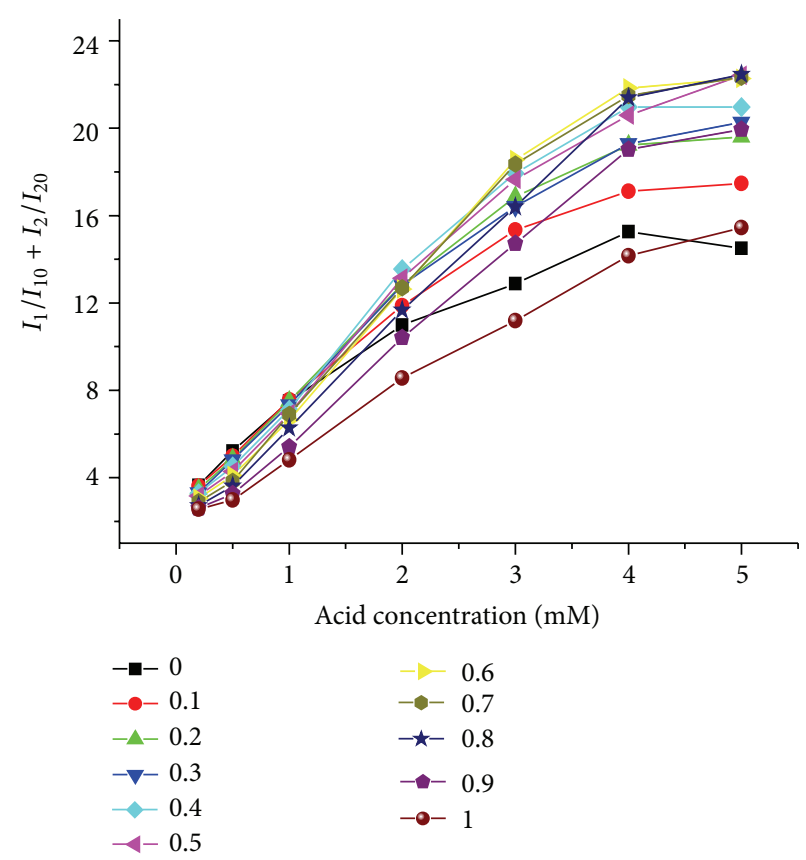

(b)

Figure 8: (a) Plot of $\left(I_{1} / I_{10}-I_{2} / I_{20}\right)$ versus $[(R)$-MA $] \%$ at varying MA concentrations (mM). (b) Plot of $\left(I_{1} / I_{10}+I_{2} / I_{20}\right)$ versus MA concentration at varying $[(R)-\mathrm{MA}] \%\left(\lambda_{\text {exc }}=290 \mathrm{~nm}\right.$, slit $\left.=4.0 / 4.0 \mathrm{~nm}\right)$. Reprinted with permission from [59]. Copyright [2010] American Chemical Society. 


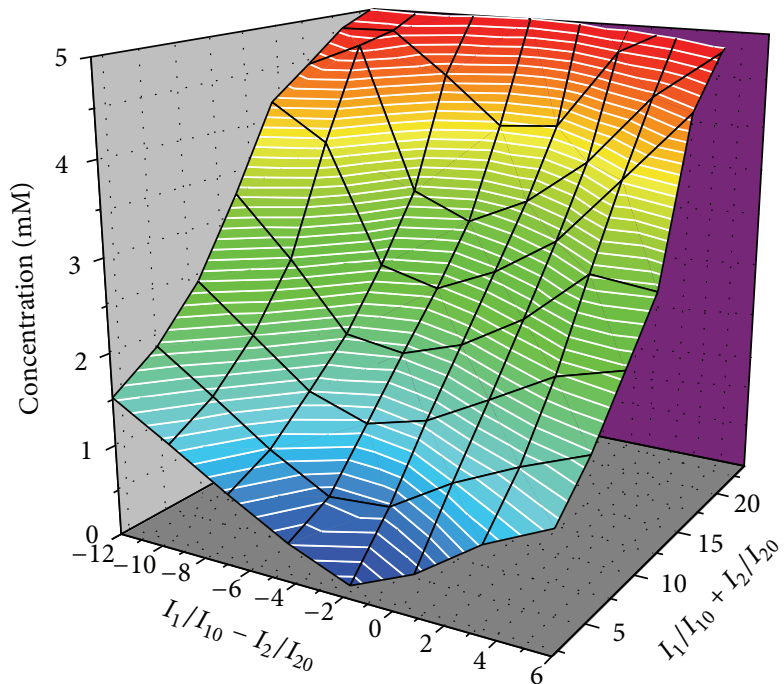

(a)

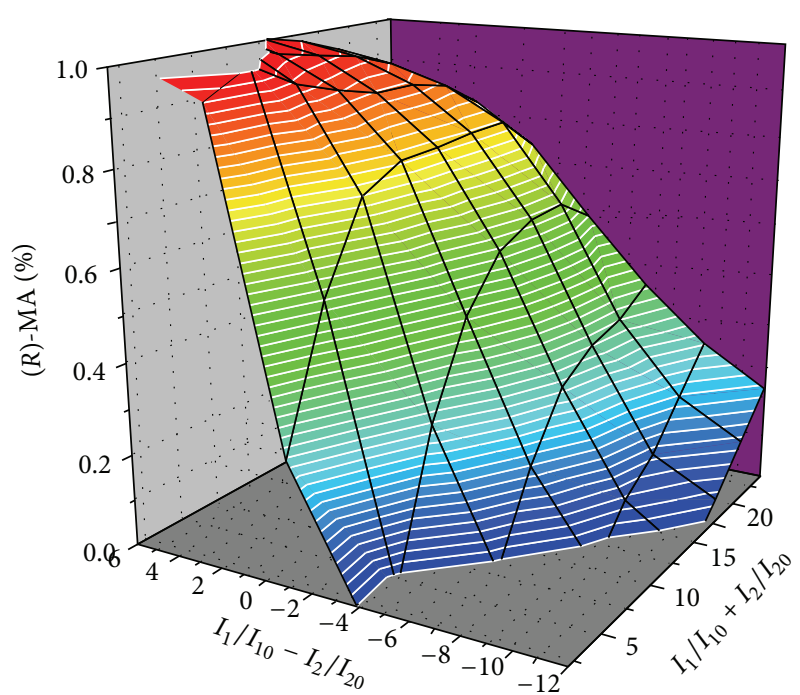

(b)

Figure 9: (a) 3D plots of $\left(I_{1} / I_{10}-I_{2} / I_{20}\right)$ and $\left(I_{1} / I_{10}+I_{2} / I_{20}\right)$ with the MA concentration (mM). (b) 3D plots of $\left(I_{1} / I_{10}-I_{2} / I_{20}\right)$ and $\left(I_{1} / I_{10}+\right.$ $\left.I_{2} / I_{20}\right)$ with $[(R)-\mathrm{MA}] \%$. Reprinted with permission from [59]. Copyright [2010] American Chemical Society.

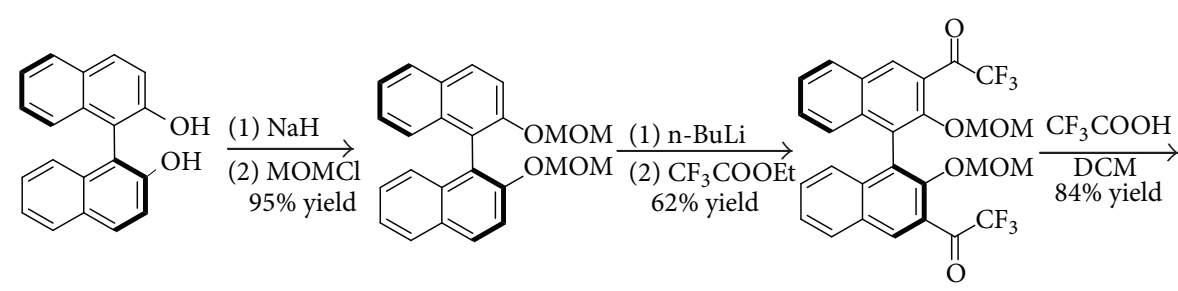<smiles>O=C(O)c1cc2ccccc2c(-c2c(C(=O)C(F)(F)F)cc3ccccc3c2O)c1O</smiles>

$(S)-11$

Scheme 2: Preparation of compound (S)-11.

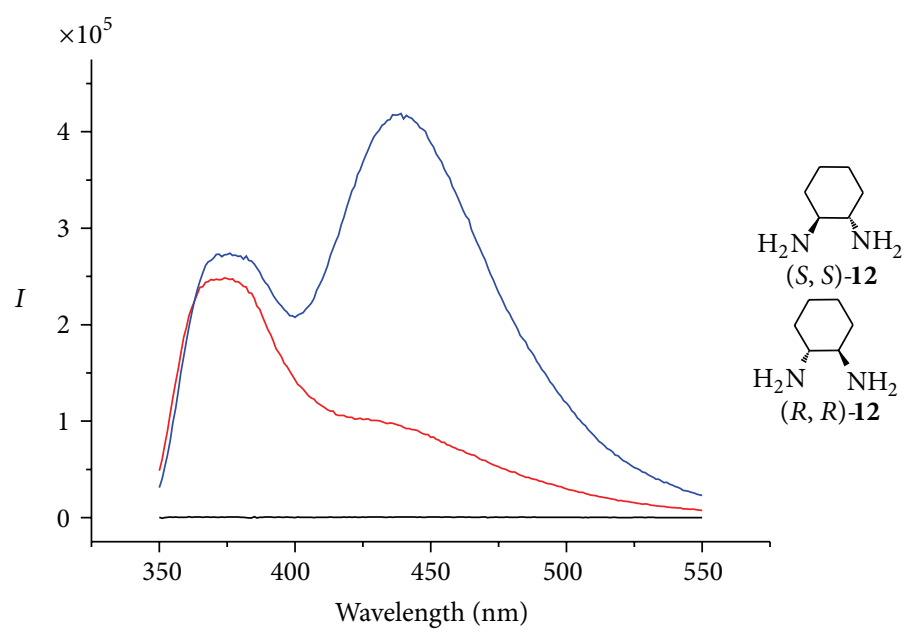

$(S)-11$

$(S)-11+(S, S)-12$

$-(S)-11+(R, R)-12$

Figure 10: Fluorescence spectra of $(S)-11\left(1.0 \times 10^{-5} \mathrm{M}\right)$ with/without $(R, R)$ - and $(S, S)-\mathbf{1 2}\left(5.0 \times 10^{-3} \mathrm{M}\right)\left(\right.$ solvent: $\mathrm{CH}_{2} \mathrm{Cl}_{2}, \lambda_{\text {exc }}=343 \mathrm{~nm}$, slit $=2 / 2 \mathrm{~nm}$ ). Reprinted with permission from [60]. Copyright [2012] American Chemical Society. 


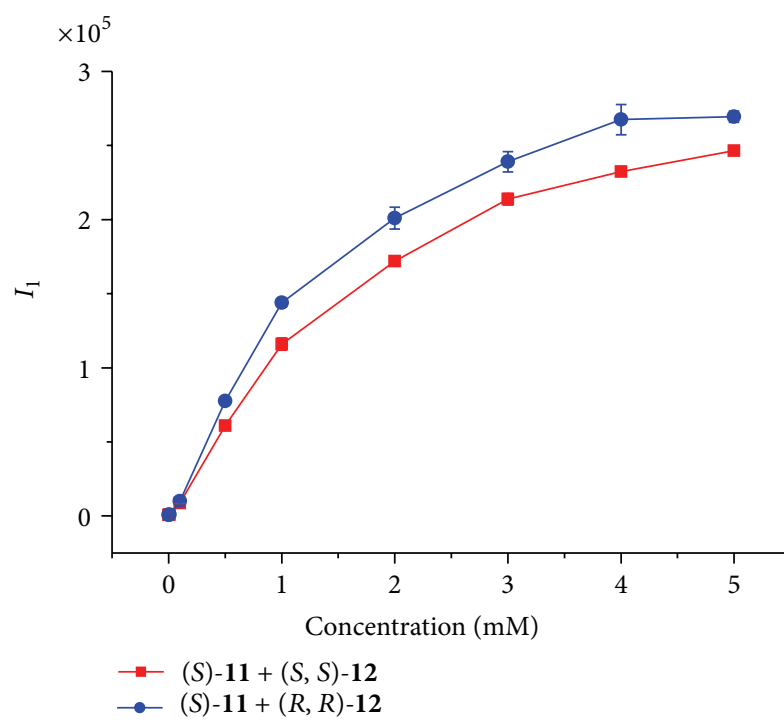

(a)

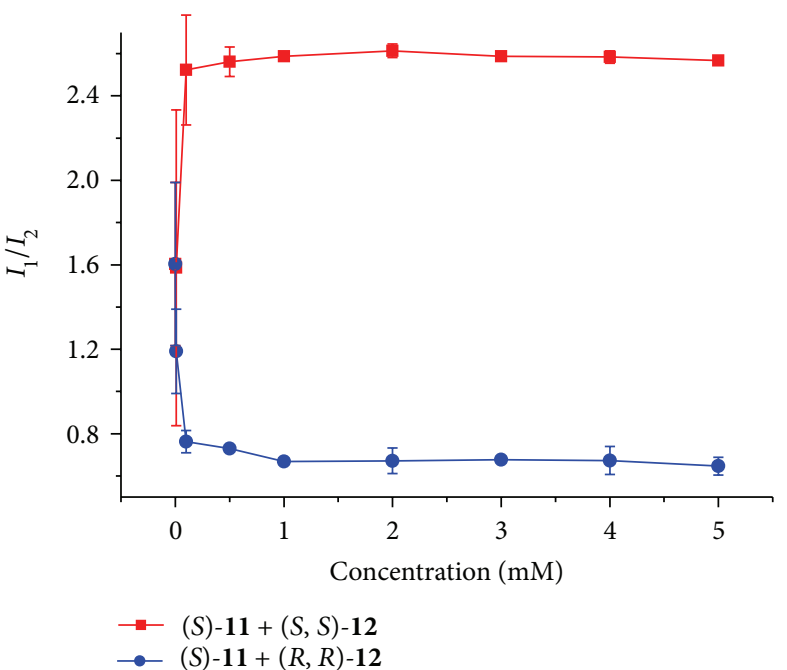

(b)

Figure 11: Plots of $I_{1}(\mathrm{a}), I_{1} / I_{2}$ (b) for $(S)$-11 $\left(1.0 \times 10^{-5} \mathrm{M}\right)$ in the presence of varying concentrations of $(R, R)$ - and $(S, S)$-12 (fluorescence intensity $I_{1}$ at $\lambda_{1}=370 \mathrm{~nm}$ and $I_{2}$ at $\lambda_{2}=438 \mathrm{~nm}$, solvent: $\mathrm{CH}_{2} \mathrm{Cl}_{2}, \lambda_{\text {exc }}=343 \mathrm{~nm}$, slit $=2 / 2 \mathrm{~nm}$ ). Reprinted with permission from [60]. Copyright [2012] American Chemical Society.

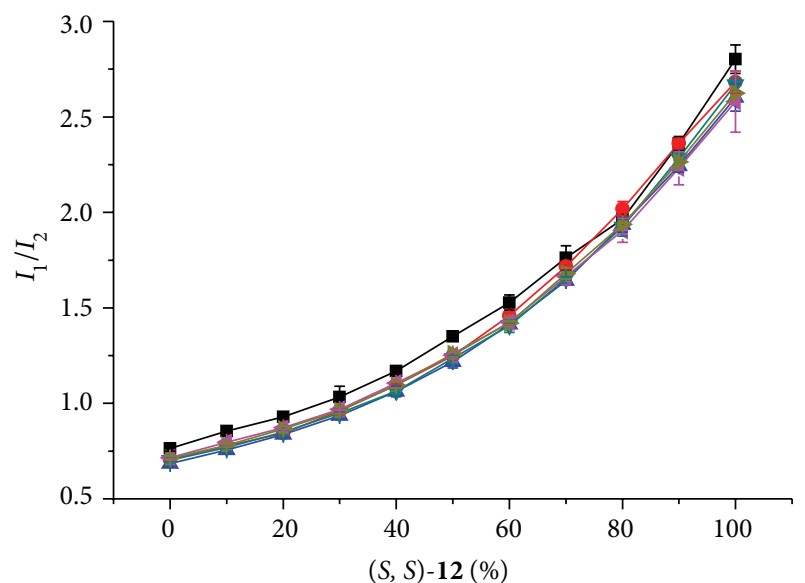

Total concentration of $\mathbf{1 2}$

$$
\begin{array}{ll}
\rightarrow 0.5 \mathrm{mM} & \rightarrow 3 \mathrm{mM} \\
\rightarrow 1 \mathrm{mM} & \leftarrow 4 \mathrm{mM} \\
\simeq 2 \mathrm{mM} & \rightarrow 5 \mathrm{mM}
\end{array}
$$

Figure 12: Plots of $I_{1} / I_{2}$ versus $(S, S)-\mathbf{1 2} \%$ at various diamine concentrations (mM) (solvent: $\mathrm{CH}_{2} \mathrm{Cl}_{2}, \lambda_{\text {exc }}=343 \mathrm{~nm}$, slit $=2 / 2 \mathrm{~nm}$ ). Reprinted with permission from [60]. Copyright [2012] American Chemical Society.

$I_{1}, I_{1}$ was used together with $I_{1} / I_{2}$ to determine the total concentration of the chiral diamine 12. Therefore, with the use of only one fluorescent sensor, both the concentration and enantiomeric composition of a chiral diamine can be simultaneously determined by one fluorescent measurement.

On the basis of the ${ }^{19} \mathrm{~F}$ NMR titration experiment for the interaction of $(S)$-11 with $(S, S)-\mathbf{1 2}$, the reaction shown in Scheme 3 was proposed. The nucleophilic addition of $(S, S)-\mathbf{1 2}$

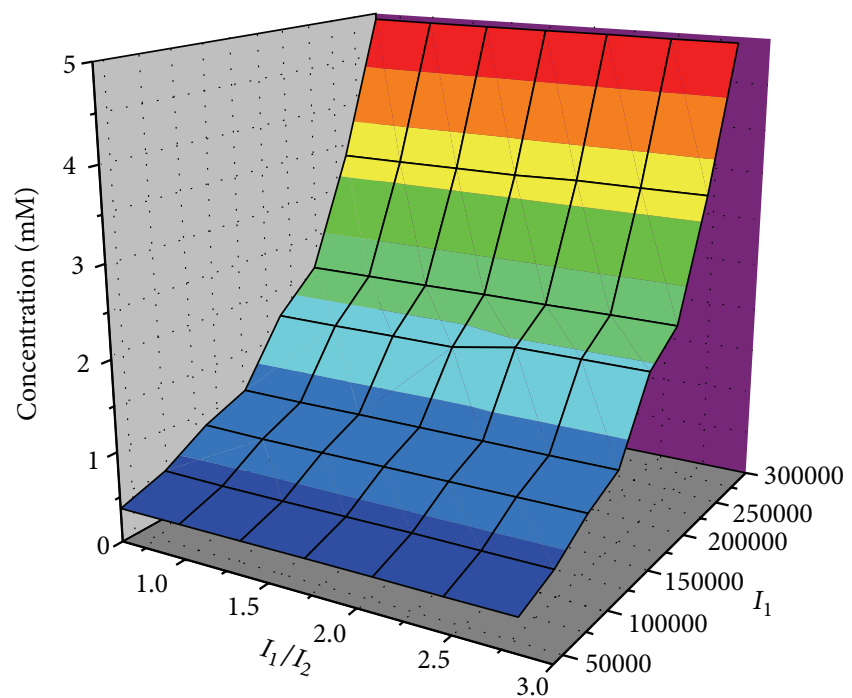

FIGURE 13: Plot of $I_{1}, I_{1} / I_{2}$ versus the total concentration of $\mathbf{1 2}$ with various enantiomeric composition. Reprinted with permission from [60]. Copyright [2012] American Chemical Society.

to the trifluoroacetyl group of $(S)$-11 occurs instantaneously to produce the hemiaminals 13 and 14; but the formation of the condensation product imine $\mathbf{1 5}$ and the subsequent cycloaddition product aminal $\mathbf{1 6}$ are slow and take a few days to complete. Since the fluorescent recognition experiments were generally conducted within $2 \mathrm{~h}$ after preparation, the observed large fluorescent enhancement of (S)-11 in the presence of the chiral diamine is attributed to the formation of the hemiaminals 13 and $\mathbf{1 4}$. The final product aminal 16 was isolated from the reaction mixture of $(S)-\mathbf{1 1}$ and $(S, S)-\mathbf{1 2}$ and its structure was confirmed by X-ray analysis (Figure 14). 


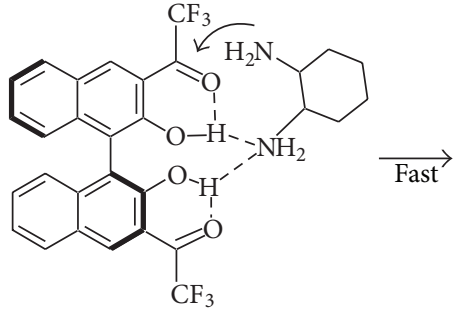

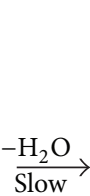<smiles>N[C@H]1CCCC[C@H]1N=C(c1cc2ccccc2c(-c2c(O)c(C(=N[C@H]3CCCC[C@H]3N)C(F)(F)F)cc3ccccc23)c1O)C(F)(F)F</smiles>

15<smiles>O=C(Oc1c(C(F)(F)F)cc2ccccc2c1-c1cc2ccccc2cc1C(O)(F)NC(I)NC1CCCCC1)C(F)(F)F</smiles>

13

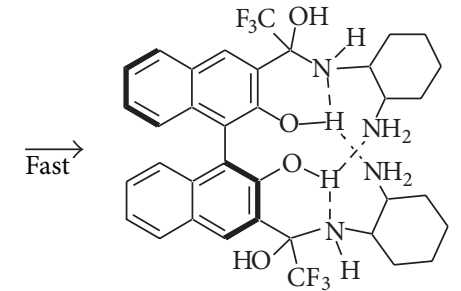

14

Scheme 3: A proposed mechanism for the reaction of $(S)$-11 with the chiral diamine 12.

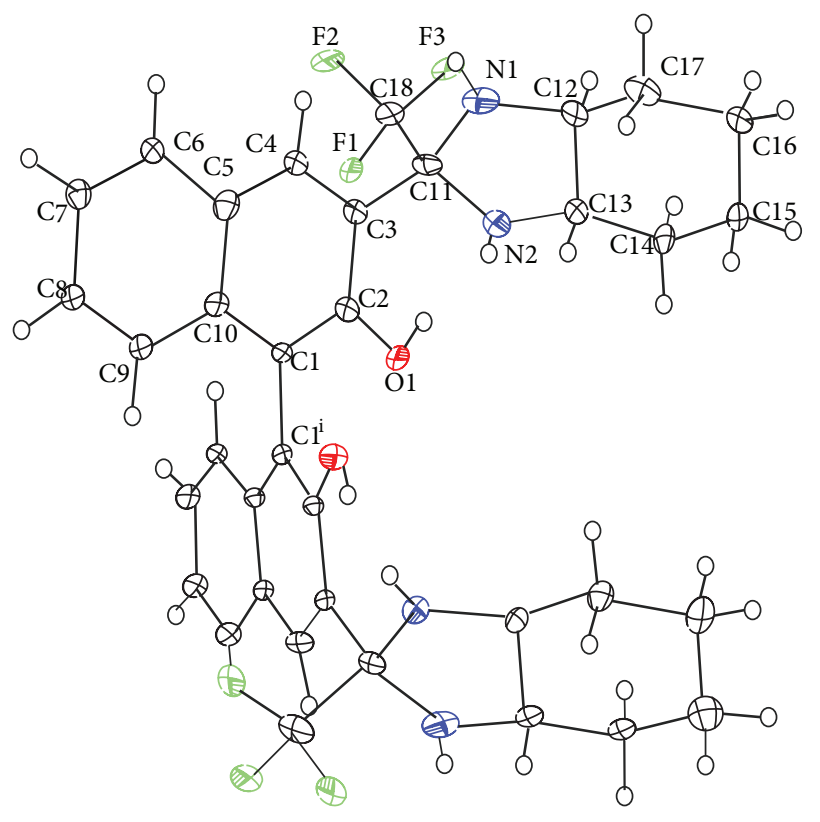

FIGURE 14: X-ray structure of the complexes of $(S)$-11 with $(S, S)-\mathbf{1 2}$. Reprinted with permission from [61]. Copyright [2013] American Chemical Society.

Although $(S)$-11 is nonemissive in methylene chloride solution, its precursor with two-MOM protecting group is highly fluorescent. This suggests that the intramolecular $\mathrm{OH} \cdots \mathrm{O}=\mathrm{C}$ hydrogen bonding of $(S)$-11 should be responsible for its diminished fluorescence. When $(S)$-11 is used to interact with the chiral diamine 12, the intermolecular hydrogen bond between one of the amine groups with the hydroxyl groups of $(S)$-11 accelerates the addition of the second amine group to the trifluoroacetyl group of $(S)-\mathbf{1 1}$,

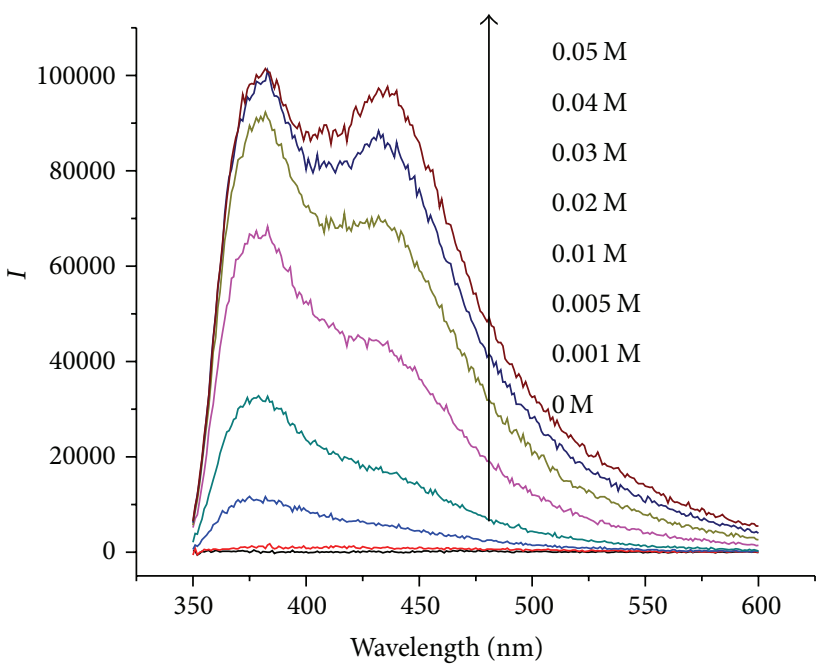

FIGURE 15: Fluorescence spectra of $(S)-\mathbf{1 1}\left(1.0 \times 10^{-5} \mathrm{M}\right.$ in $\left.\mathrm{CH}_{2} \mathrm{Cl}_{2}\right)$ in the presence of propylamine at $0-0.05 \mathrm{M}\left(\lambda_{\mathrm{exc}}=343 \mathrm{~nm}\right.$, slit $=$ 2.0/2.0 nm). Reprinted with permission from [61]. Copyright [2013] American Chemical Society.

producing the resulting hemiaminal products 13 and $\mathbf{1 4}$, in which the original $\mathrm{O}-\mathrm{H} \cdots \mathrm{O}=\mathrm{C}$ hydrogen bonds in $(S)-11$ have been disrupted to generate the observed dual emissions. The short-wavelength emission is ascribed to the nucleophilic addition of one amine group to the carbonyl group and the long-wavelength emission is ascribed to hydrogen-bonding interaction of the second amine group with the hydroxyl groups of the sensor.

The proposed interaction of $(S)$-11 with the diamine is supported by the fluorescent responses of $(S)$-11 toward propylamine as shown in Figure 15. Much higher concentration of the monoamine than the diamine was required to turn 


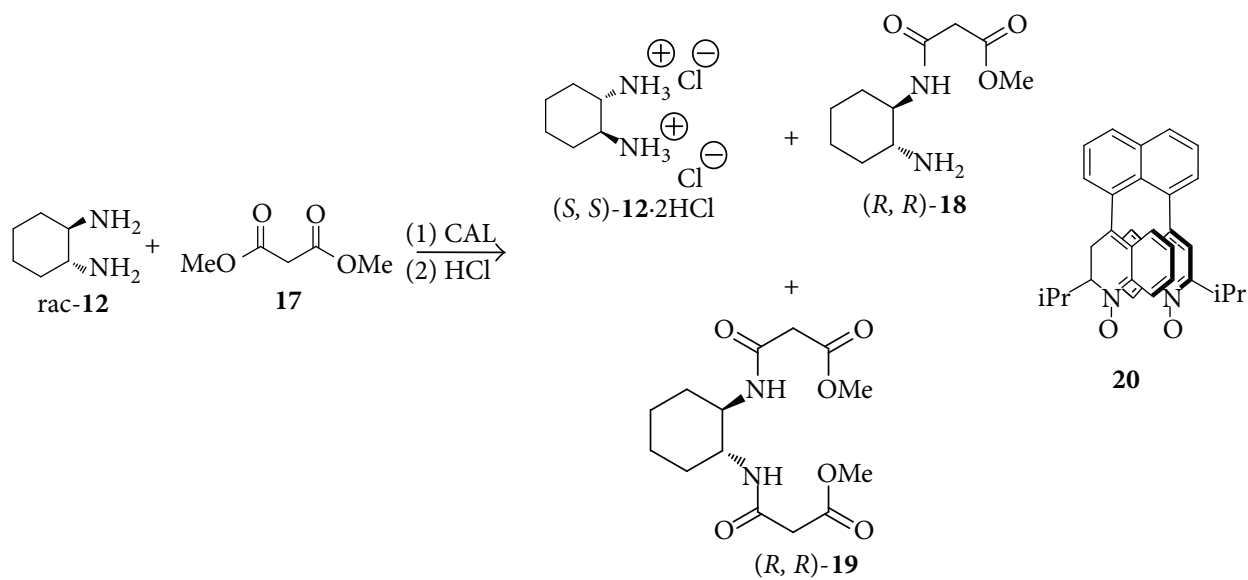

Scheme 4: Enzymatic kinetic resolution of racemic 1,2-diamine 12.
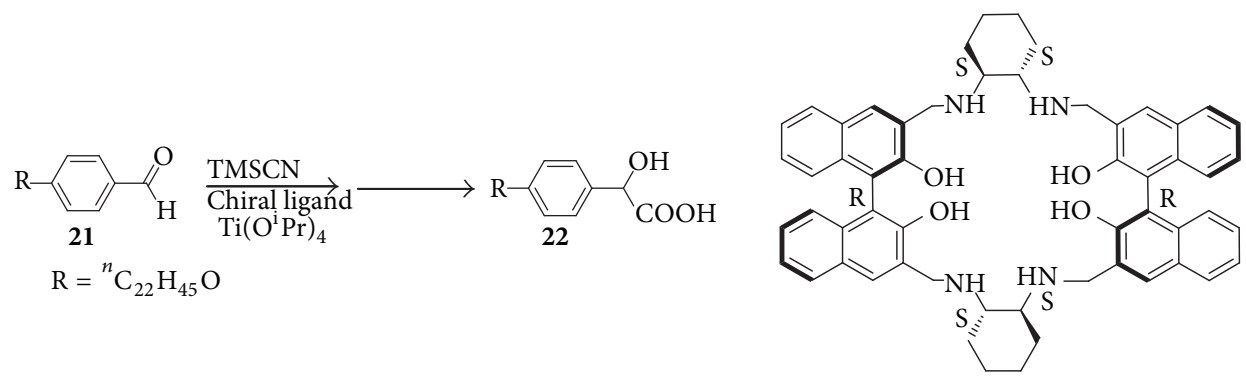

$(R)-7$

Scheme 5: Asymmetric reaction of $\mathbf{2 1}$ to generate $\mathbf{2 2}$

on the fluorescence of $(S)$-11. The fluorescent enhancement first occurred at the short wavelength. Only at even higher concentrations of propylamine, was there more fluorescent enhancement at the long wavelength emission. These observations suggest that the short wavelength emission of $(S)$ 11 might be due to the addition of propylamine to the trifluoroacetyl group. The resulting product upon further interaction with propylamine probably via hydrogen bonding with the naphthyl hydroxyl groups could lead to the long wavelength emission.

\section{Summary and Outlook}

In this paper, we have described two strategies to simultaneously determine the concentration and enantiomeric composition of a chiral compound by one fluorescent measurement. One strategy uses a pseudoenantiomeric fluorescent sensor pair in which each sensor shows greater fluorescent enhancement at a different wavelength upon interaction with one of the enantiomers of a chiral substrate. In another strategy, a fluorescent sensor responds differently toward the two enantiomers of a chiral compound at two emitting wavelengths. These two strategies could significantly simplify the practical application of the enantioselective fluorescent sensors.

One of the potential applications of an enantioselective fluorescent sensor is in high-throughput chiral catalyst screening for asymmetric catalysis. For example, Tumambac and Wolf reported the use of enantioselective fluorescent sensing in the enzymatic kinetic resolution of trans-1,2diaminocyclohexane (Scheme 4) [62]. After the reaction, the diamine 12 and the monoaminoester 18 could be isolated through precipitation with $2 \mathrm{~N} \mathrm{HCl}$ followed by basic extraction. Then the enantioselective fluorescent sensor $\mathbf{2 0}$ was used to determine the enantiomeric composition of 12. Our group also developed a soluble "supported" chiral acid system for the chiral catalyst screening (Scheme 5) [57]. The aldehyde 21 was transformed to the chiral $\alpha$-hydroxy acid 22 by asymmetric reaction with TMSCN in the presence of a chiral catalyst followed by hydrolysis. The acid $\mathbf{2 2}$ containing a 22carbon chain alkyl group was found to be almost insoluble in most of the organic solvents but with good solubility in THF. Therefore, the product could be precipitated out in the absence of THF and all the catalysts and reagents could be removed. Then the enantiomeric composition was determined in the homogeneous THF solution with the use of the enantioselective fluorescent sensor $(R)-7$.

The examples described above are the only reports on the direct application of enantioselective fluorescent sensors in chiral catalyst screening for asymmetric reaction. Although recent years have seen significant development in enantioselective fluorescent sensing, there are still significant challenges for the use of enantioselective fluorescent sensors in the analysis of asymmetric reactions. Most of the studies 
were conducted only in the recognition of isolated pure substrate samples. In the actual reaction mixture, many substances such as catalysts, additives, byproducts, and solvents could potentially interfere with the fluorescent recognition of the chiral products and add uncertainty to the analysis. Another challenge is to expand the substrate scope of the enantioselective fluorescent sensors. In addition to the highly functionalized substrates such as $\alpha$-hydroxycarboxylic acids, diamines, amino alcohols, and amino acids, enantioselective fluorescent sensors that can recognize chiral molecules with less strongly interacting groups such as alcohols, ethers, esters, or even molecules without a polar functional group are also needed. We believe that with the great effort and creativity of the researchers in this area it should be possible to meet all these challenges and allow the enantioselective fluorescent sensing to be developed into a practically useful analytical tool in chiral assay.

\section{Conflict of Interests}

The authors declare that there is no conflict of interests regarding the publication of this paper.

\section{References}

[1] E. L. Izake, "Improving memory performance in the aged through mnemonic training: a meta-analytic study," Psychology and Aging, vol. 96, no. 7, pp. 1659-1676, 2007.

[2] M. C. Núñez, M. E. García-Rubiño, A. Conejo-García et al., "Homochiral drugs: a demanding tendency of the pharmaceutical industry," Current Medicinal Chemistry, vol. 16, no. 16, pp. 2064-2074, 2009.

[3] R. Natarajan and S. C. Basak, "Numerical descriptors for the characterization of chiral compounds and their applications in modeling biological and toxicological activities," Current Topics in Medicinal Chemistry, vol. 11, no. 7, pp. 771-787, 2011.

[4] M. Herrero, C. Simó, V. García-Cañas, S. Fanali, and A. Cifuentes, "Chiral capillary electrophoresis in food analysis," Electrophoresis, vol. 31, no. 13, pp. 2106-2114, 2010.

[5] C. Simó, C. Barbas, and A. Cifuentes, "Chiral electromigration methods in food analysis," Electrophoresis, vol. 24, no. 15, pp. 2431-2441, 2003.

[6] "FDA'S policy statement for the development of new stereoisomeric drugs," Chirality, vol. 4, no. 5, pp. 338-340, 1992.

[7] M. Christmann and S. Brase, Asymmetric Synthesis: The Essentials, John Wiley \& Sons, New York, NY, USA, 2007.

[8] G.-Q. Lin, Y.-M. Li, and A. S. C. Chan, Principles and Applications of Asymmetric Synthesis, John Wiley \& Sons, New York, NY, USA, 2001.

[9] W. F. Maier, K. Stowe, and S. Sieg, "Combinatorial and highthroughput materials science," Angewandte Chemie, vol. 46, no. 32, pp. 6016-6067, 2007.

[10] P. T. Corbett, J. Leclaire, L. Vial et al., "Dynamic combinatorial chemistry," Chemical Reviews, vol. 106, no. 9, pp. 3652-3711, 2006.

[11] S. Senkan, "Combinatorial heterogeneous catalysis-a new path in an old field," Angewandte Chemie-International Edition, vol. 40, no. 2, pp. 312-329, 2001.
[12] B. Jandeleit, D. J. Schaefer, T. S. Powers, H. W. Turner, and W. H. Weinberg, "Combinatorial materials science and catalysis," Angewandte Chemie, vol. 38, no. 17, pp. 2494-2532, 1999.

[13] M. T. Reetz, "Combinatorial and evolution-based methods in the creation of enantioselective catalysts," Angewandte ChemieInternational Edition, vol. 40, no. 2, pp. 284-310, 2001.

[14] M. Tsukamoto and H. B. Kagan, "Recent advances in the measurement of enantiomeric excesses," Advanced Synthesis \& Catalysis, vol. 344, no. 5, pp. 453-463, 2002.

[15] J. F. Traverse and M. L. Snapper, "High-throughput methods for the development of new catalytic asymmetric reactions," Drug Discovery Today, vol. 7, no. 19, pp. 1002-1012, 2002.

[16] M. G. Finn, "Emerging methods for the rapid determination of enantiomeric excess," Chirality, vol. 14, no. 7, pp. 534-540, 2002.

[17] D. Leung, S. O. Kang, and E. V. Anslyn, "Rapid determination of enantiomeric excess: a focus on optical approaches," Chemical Society Reviews, vol. 41, no. 1, pp. 448-479, 2012.

[18] D. G. I. Petra, J. N. H. Reek, P. C. J. Kamer, H. E. Schoemaker, and P. W. N. M. van Leeuwen, "IR spectroscopy as a highthroughput screening-technique for enantioselective hydrogentransfer catalysts," Chemical Communications, no. 8, pp. 683$684,2000$.

[19] M. T. Reetz, M. H. Becker, K. M. Kuhling, and A. Holzwarth, "Time-resolved IR-thermographic detection and screening of enantioselectivity in catalytic reactions," Angewandte ChemieInternational Edition, vol. 37, no. 19, pp. 2647-2650, 1998.

[20] P. Tielmann, M. Boese, M. Luft, and M. T. Reetz, "A practical high-throughput screening system for enantioselectivity by using FTIR spectroscopy," Chemistry, vol. 9, no. 16, pp. 3882$3887,2003$.

[21] N. Millot, P. Borman, M. S. Anson, I. B. Campbell, S. J. F. Macdonald, and M. Mahmoudian, "Rapid determination of enantiomeric excess using infrared thermography," Organic Process Research and Development, vol. 6, no. 4, pp. 463-470, 2002.

[22] P. Chen, "Electrospray ionization tandem mass spectrometry in high-throughput screening of homogeneous catalysts," Angewandte Chemie-International Edition, vol. 42, no. 25, pp. 28322847, 2003.

[23] H. Liu, C. Felten, Q. Xue et al., "Development of multichannel devices with an array of electrospray tips for high-throughput mass spectrometry," Analytical Chemistry, vol. 72, no. 14, pp. 3303-3310, 2000.

[24] J. H. Guo, J. Y. Wu, G. Siuzdak, and M. G. Finn, "Measurement of enantiomeric excess by kinetic resolution and mass spectrometry," Angewandte Chemie-International Edition, vol. 38, no. 12, pp. 1755-1758, 1999.

[25] W. Schrader, A. Eipper, D. Jonathan Pugh, and M. T. Reetz, "Second-generation MS-based high-throughput screening system for enantioselective catalysts and biocatalysts," Canadian Journal of Chemistry, vol. 80, no. 6, pp. 626-632, 2002.

[26] M. T. Reetz, M. H. Becker, H. W. Klein, and D. Stockigt, "A method for high-throughput screening of enantioselective catalysts," Angewandte Chemie-International Edition, vol. 38, no. 12, pp. 1758-1761, 1999.

[27] M. T. Reetz, K. M. Kuhling, A. Deege, H. Hinrichs, and D. Belder, Super-high-throughput screening of enantioselective catalysts by using capillary array electrophoresis, vol. 39, no. 21, pp. 3891-3893, 2000.

[28] M. T. Reetz, A. Zonta, K. Schimossek, K. Liebeton, and K. Jaeger, "Creation of enantioselective biocatalysts for organic chemistry 
by in vitro evolution," Angewandte Chemie, vol. 36, no. 24, pp. 2830-2832, 1997.

[29] D. Leung and E. V. Anslyn, “Transitioning enantioselective indicator displacement assays for $\alpha$-amino acids to protocols amenable to high-throughput screening," Journal of the American Chemical Society, vol. 130, no. 37, pp. 12328-12333, 2008.

[30] D. Leung, J. F. Folmer-Andersen, V. M. Lynch, and E. V. Anslyn, "Using enantioselective indicator displacement assays to determine the enantiomeric excess of $\alpha$-amino acids," Journal of the American Chemical Society, vol. 130, no. 37, pp. 1231812327, 2008.

[31] K. Ding, A. Ishii, and K. Mikami, "Super high throughput screening (SHTS) of chiral ligands and activators: asymmetric activation of chiral diol-zinc catalysts by chiral nitrogen activators for the enantioselective addition of diethylzinc to aldehydes," Angewandte Chemie - International Edition, vol. 38, no. 4, pp. 497-501, 1999.

[32] S. Nieto, V. M. Lynch, E. V. Anslyn, H. Kim, and J. Chin, "Highthroughput screening of identity, enantiomeric excess, and concentration using MLCT transitions in CD spectroscopy," Journal of the American Chemical Society, vol. 130, no. 29, pp. 9232-9233, 2008.

[33] G. T. Copeland and S. J. Miller, "A chemosensor-based approach to catalyst discovery in solution and on solid support," Journal of the American Chemical Society, vol.121, no. 17, pp. 4306-4307, 1999.

[34] G. A. Korbel, G. Lalic, and M. D. Shair, "Reaction microarrays: a method for rapidly determining the enantiomeric excess of thousands of samples," Journal of the American Chemical Society, vol. 123, no. 2, pp. 361-362, 2001.

[35] X. Mei and C. Wolf, "Determination of enantiomeric excess and concentration of unprotected amino acids, amines, amino alcohols, and carboxylic acids by competitive binding assays with a chiral scandium complex," Journal of the American Chemical Society, vol. 128, no. 41, pp. 13326-13327, 2006.

[36] X. Mei and C. Wolf, "Determination of enantiomeric excess and concentration of chiral compounds using a 1,8-diheteroarylnaphthalene-derived fluorosensor," Tetrahedron Letters, vol. 47, no. 45, pp. 7901-7904, 2006.

[37] S. Liu, J. P. C. Pestano, and C. Wolf, "Enantioselective fluorescence sensing of chiral $\alpha$-amino alcohols," Journal of Organic Chemistry, vol. 73, no. 11, pp. 4267-4270, 2008.

[38] C. Wolf, S. Liu, and B. C. Reinhardt, "An enantioselective fluorescence sensing assay for quantitative analysis of chiral carboxylic acids and amino acid derivatives," Chemical Communications, no. 40, pp. 4242-4244, 2006.

[39] K. W. Bentley and C. Wolf, "Stereodynamic chemosensor with selective circular dichroism and fluorescence readout for in situ determination of absolute configuration, enantiomeric excess, and concentration of chiral compounds," Journal of the American Chemical Society, vol. 135, no. 33, pp. 12200-12203, 2013.

[40] P. Zhang and C. Wolf, "Sensing of the concentration and enantiomeric excess of chiral compounds with tropos ligand derived metal complexes," Chemical Communications, vol. 49, no. 62, pp. 7010-7012, 2013.

[41] L. Zhu and E. V. Anslyn, "Facile quantification of enantiomeric excess and concentration with indicator-displacement assays: an example in the analyses of $\alpha$-hydroxyacids," Journal of the American Chemical Society, vol. 126, no. 12, pp. 3676-3677, 2004.

[42] L. Zhu, S. H. Shabbir, and E. V. Anslyn, "Two methods for the determination of enantiomeric excess and concentration of a chiral sample with a single spectroscopic measurement," Chemistry, vol. 13, no. 1, pp. 99-104, 2007.

[43] S. H. Shabbir, L. A. Joyce, G. M. da Cruz, V. M. Lynch, S. Sorey, and E. V. Anslyn, "Pattern-based recognition for the rapid determination of identity, concentration, and enantiomeric excess of subtly different threo diols," Journal of the American Chemical Society, vol. 131, no. 36, pp. 13125-13131, 2009.

[44] S. Nieto, J. M. Dragna, and E. V. Anslyn, "A facile circular dichroism protocol for rapid determination of enantiomeric excess and concentration of chiral primary amines," Chemistry, vol. 16, no. 1, pp. 227-232, 2010.

[45] L. Pu, "Fluorescence of organic molecules in chiral recognition," Chemical Reviews, vol. 104, no. 3, pp. 1687-1716, 2004.

[46] L. Pu, "Enantioselective fluorescent sensors: a tale of BINOL," Accounts of Chemical Research, vol. 45, no. 2, pp. 150-163, 2012.

[47] T. D. James, K. R. A. S. Sandanayake, and S. Shinkal, "Chiral discrimination of monosaccharides using a fluorescent molecular sensor," Nature, vol. 374, no. 6520, pp. 345-347, 1995.

[48] M. T. Reetz and S. Sostmann, "2,15-Dihydroxy-hexahelicene (HELIXOL): synthesis and use as an enantioselective fluorescent sensor," Tetrahedron, vol. 57, no. 13, pp. 2515-2520, 2001.

[49] W. Wong, K. Huang, P. Teng, C. Lee, and H. Kwong, "A novel chiral terpyridine macrocycle as a fluorescent sensor for enantioselective recognition of amino acid derivatives," Chemical Communications, vol. 10, no. 4, pp. 384-385, 2004.

[50] J. Zhao, T. M. Fyles, and T. D. James, "Chiral binol-bisboronic acid as fluorescence sensor for sugar acids," Angewandte Chemie - International Edition, vol. 43, no. 26, pp. 3461-3464, 2004.

[51] S. Pagliari, R. Corradini, G. Galaverna et al., "Enantioselective fluorescence sensing of amino acids by modified cyclodextrins: role of the cavity and sensing mechanism," Chemistry, vol. 10, no. 11, pp. 2749-2758, 2004.

[52] H. Matsushita, N. Yamamoto, M. M. Meijler et al., "Chiral sensing using a blue fluorescent antibody," Molecular BioSystems, vol. 1, no. 4, pp. 303-306, 2005.

[53] X. F. Mei and C. Wolf, "A highly congested N,N/-dioxide fluorosensor for enantioselective recognition of chiral hydrogen bond donors," Chemical Communications, vol. 10, no. 18, pp. 20782079, 2004.

[54] X. Mei and C. Wolf, "Enantioselective sensing of chiral carboxylic acids," Journal of the American Chemical Society, vol. 126, no. 45, pp. 14736-14737, 2004.

[55] V. J. Pugh, Q. S. Hu, and L. Pu, “The first dendrimer-based enantioselective fluorescent sensor for the recognition of chiral amino alcohols," Angewandte Chemie, vol. 39, no. 20, pp. 36383641, 2000.

[56] L. Z. Gong, Q. S. Hu, and L. Pu, "Optically active dendrimers with a binaphthyl core and phenylene dendrons: light harvesting and enantioselective fluorescent sensing," Journal of Organic Chemistry, vol. 66, no. 7, pp. 2358-2367, 2001.

[57] Z. B. Li, J. Lin, Y. C. Qin, and L. Pu, "Enantioselective fluorescent recognition of a soluble "supported" chiral acid: toward a new method for chiral catalyst screening," Organic Letters, vol. 7, no. 16, pp. 3441-3444, 2005.

[58] H. L. Liu, Q. Peng, Y. D. Wu et al., "Highly enantioselective recognition of structurally diverse $\alpha$-Hydroxycarboxylic acids using a fluorescent sensor," Angewandte Chemie: International Edition, vol. 49, no. 3, pp. 602-606, 2010.

[59] S. Yu and L. Pu, "Pseudoenantiomeric fluorescent sensors in a chiral assay," Journal of the American Chemical Society, vol. 132, no. 50, pp. 17698-17700, 2010. 
[60] S. Yu, W. Plunkett, M. Kim, and L. Pu, "Simultaneous determination of both the enantiomeric composition and concentration of a chiral substrate with one fluorescent sensor," Journal of the American Chemical Society, vol. 134, no. 50, pp. 20282-20285, 2012.

[61] S. S. Yu, W. Plunkett, M. Kim, E. Wu, M. Sabat, and L. Pu, "Molecular recognition of aliphatic diamines by $3,3^{\prime}$-di(trifluoroacetyl)-1,1'-bi-2-naphthol," Journal of Organic Chemistry, vol. 78, pp. 12671-12680, 2013.

[62] G. E. Tumambac and C. Wolf, "Enantioselective analysis of an asymmetric reaction using a chiral fluorosensor," Organic Letters, vol. 7, no. 18, pp. 4045-4048, 2005. 

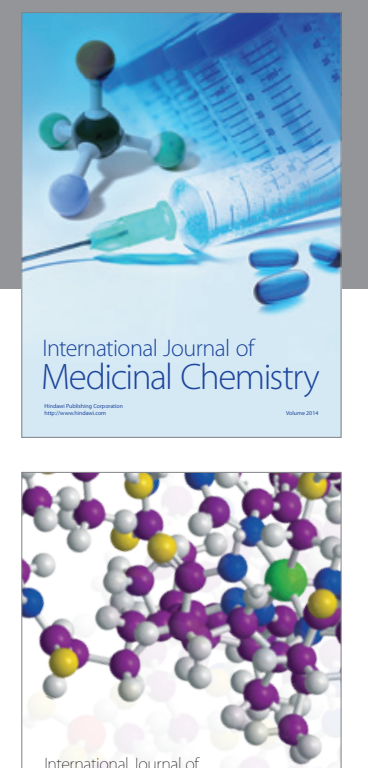

\section{Carbohydrate} Chemistry

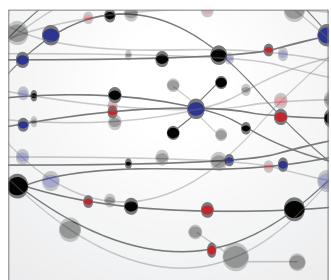

The Scientific World Journal
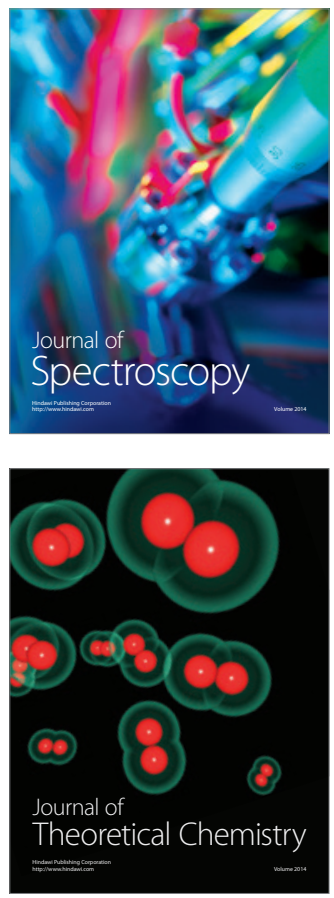
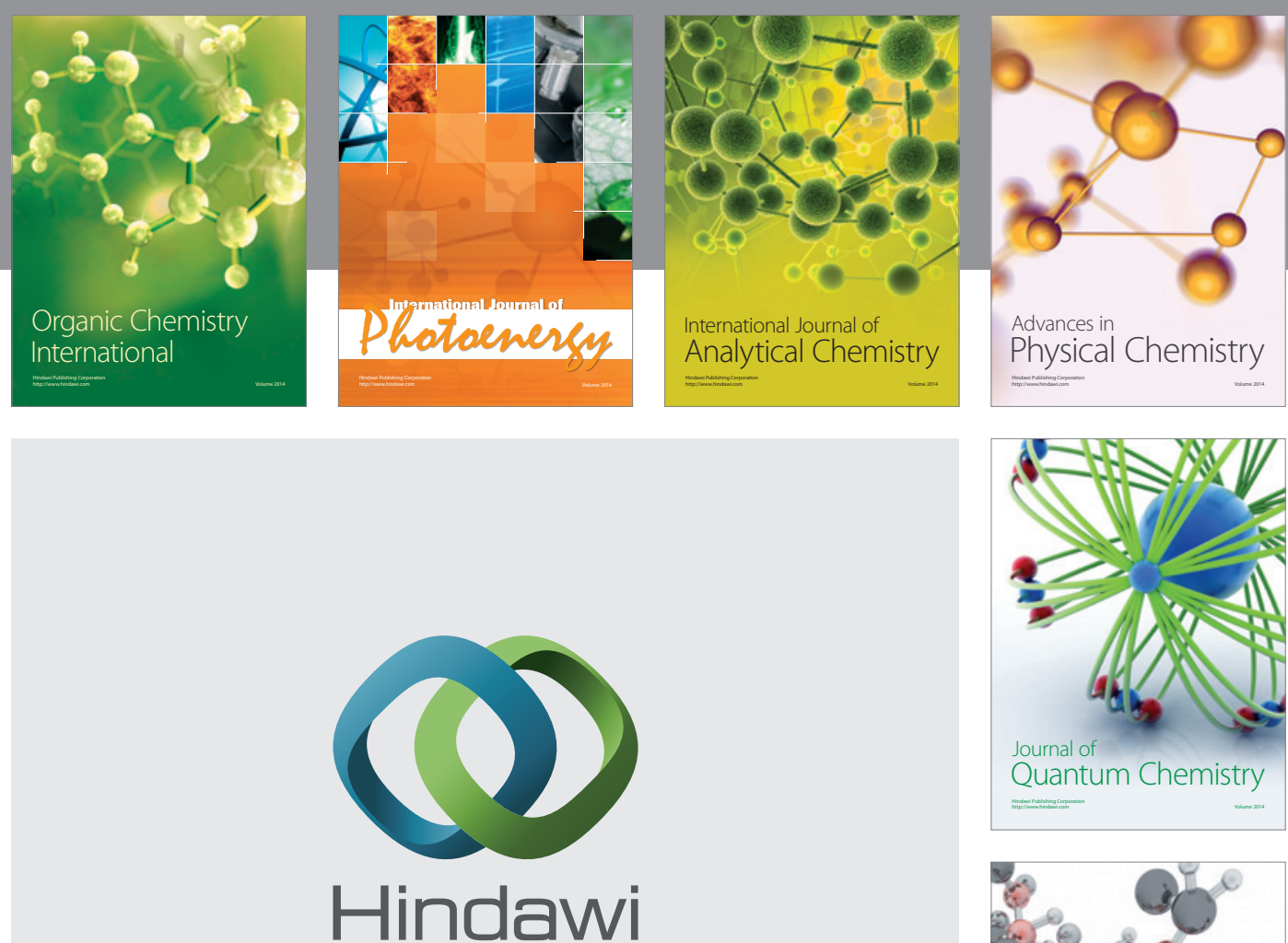

Submit your manuscripts at

http://www.hindawi.com

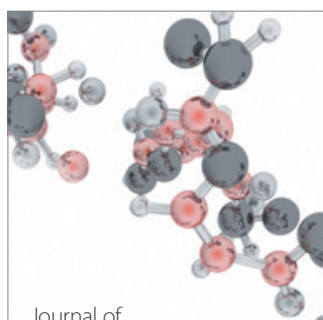

Analytical Methods

in Chemistry

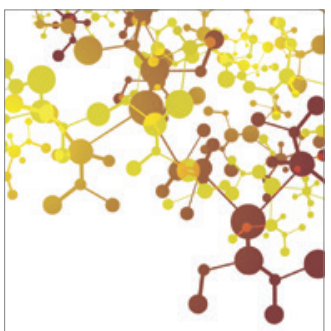

Journal of

Applied Chemistry

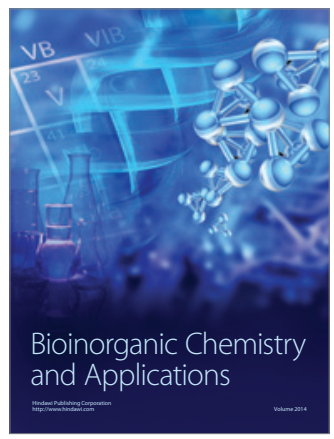

Inorganic Chemistry
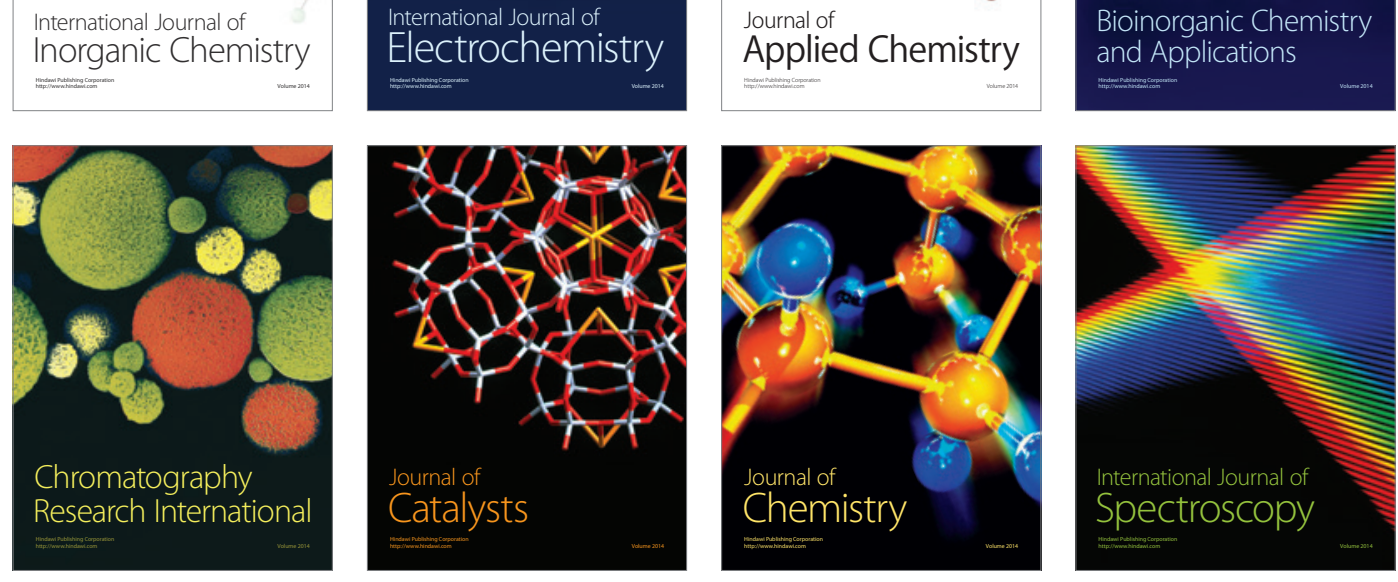